\title{
The production of 4,182 mouse lines identifies experimental and biological variables
}

\section{impacting Cas9-mediated mutant mouse line production}

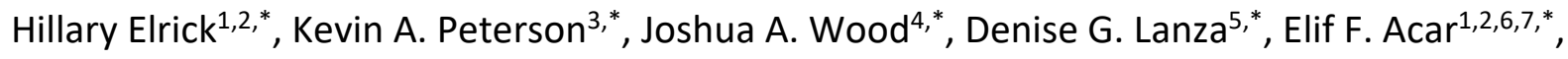

Lydia Teboul ${ }^{8,}{ }^{*}$, Edward J. Ryder ${ }^{9,}{ }^{*}$, Shinya Ayabe ${ }^{10}$, Marie-Christine Birling $^{11}$, Adam Caulder $^{8}$,

Francesco Chiani ${ }^{12}$, Gemma F. Codner ${ }^{8}$, Brendan Doe ${ }^{9}$, Graham Duddy $^{9}$, Alessia Gambadoro ${ }^{12}$,

Marina Gertsenstein ${ }^{1}$, Alba Gomez-Segura ${ }^{13}$, Leslie O. Goodwin ${ }^{3}$, Cunxiang Ju ${ }^{14,30}$, Petr

Kasparek $^{15}$, Ruairidh King ${ }^{16}$, Daekee Lee ${ }^{17,18}$, Ho Lee ${ }^{17,19}$, Lauri G. Lintott ${ }^{1,2}$, Zhiwei Liu ${ }^{20}$, Isabel

Lorenzo $^{5}$, Matthew Mackenzie $^{8}$, Susan Marschall ${ }^{21}$, Peter Matthews ${ }^{13,21}$, Mark Ruhe ${ }^{4}$, Luis

Santos $^{16}$, John R. Seavitt ${ }^{5}$, Claudia Seisenberger ${ }^{22}$, Hannah Wardle-Jones ${ }^{9}$, Brandon J. Willis ${ }^{4}$, Jie

Zhang $^{20}$, Jing Zhao ${ }^{14,30}$, Fei Zhou ${ }^{20}$, David J. Adams ${ }^{9}$, Allan Bradley ${ }^{9}$, Robert E. Braun ${ }^{3}$, Francesco

J. DeMayo ${ }^{24,32}$, Mary E. Dickinson ${ }^{5,23}$, Xiang Gao ${ }^{14}$, Yann Hérault ${ }^{11}$, Martin Hrabĕ de

Angelis $^{21,25,26}$, K. C. Kent Lloyd ${ }^{4,27}$, Ann-Marie Mallon ${ }^{16}$, Fabio Mammano ${ }^{12}$, Colin McKerlie ${ }^{2}$,

Terrence Meehan ${ }^{13,33}$, Helen Parkinson ${ }^{13}$, Ramiro Ramirez-Solis ${ }^{9}$, Radislav Sedlacek ${ }^{15}$, Je Kyung

Seong ${ }^{17,28}$, William C. Skarnes ${ }^{9,34}$, Damien Smedley ${ }^{29}$, Masaru Tamura ${ }^{10}$, Sara Wells ${ }^{8}$, Jacqueline

K. White ${ }^{3}$, Wolfgang Wurst ${ }^{22,25}$, Atsushi Yoshiki ${ }^{10}$, International Mouse Phenotyping

Consortium", Stephen A. Murray ${ }^{3}$, Jason D. Heaney ${ }^{5}$, Lauryl M. J. Nutter ${ }^{1,2, \S}$

*equal contribution

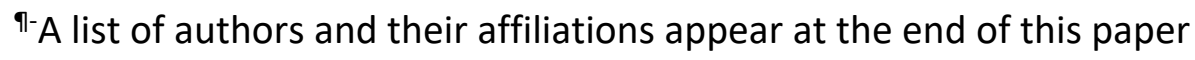

§corresponding author, lauryl.nutter@sickkids.ca

${ }^{1}$ The Centre for Phenogenomics, Toronto, ON, Canada, M5T 3H7

${ }^{2}$ The Hospital for Sick Children, Toronto, ON, Canada, M5G 1X8 
${ }^{3}$ The Jackson Laboratory, Bar Harbor, ME, USA, 04609

${ }^{4}$ Mouse Biology Program, University of California-Davis, California, USA, 95618

${ }^{5}$ Department of Molecular and Human Genetic, Baylor College of Medicine, Houston, TX, USA, 77030

${ }^{6}$ Department of Statistics, University of Manitoba, Winnipeg, MB, Canada, R3T 2N2

${ }^{7}$ Department of Statistical Sciences, University of Toronto, Toronto, ON, Canada, M5G 1 Z5

${ }^{8}$ The Mary Lyon Centre, MRC Harwell Institute, Harwell Campus, Didcot, Oxon, OX11 ORD, UK

${ }^{9}$ Wellcome Sanger Institute, Wellcome Genome Campus, Hinxton, Cambridge, CB10 1SA, UK

${ }^{10}$ RIKEN BioResource Research Center, Tsukuba, Ibaraki, Japan, 305-0074

${ }^{11}$ Université de Strasbourg, CNRS, INSERM, CELPHEDIA, PHENOMIN, Institut Clinique de la Souris, Illkirch-Graffenstaden, France

${ }^{12} \mathrm{CNR}$ Institute of Biochemistry and Cell Biology - Monterotondo, Rome, Italy 00015

${ }^{13}$ European Molecular Biology Laboratory-European Bioinformatics Institute, Wellcome Genome Campus, Hinxton, UK

${ }^{14}$ Model Animal Research Center of Nanjing University, Nanjing University, Nanjing, China 210061

${ }^{15}$ Czech Centre for Phenogenomics, Division BIOCEV, Institute of Molecular Genetics of the Czech Academy of Sciences, Vestec, Czech Republic

${ }^{16} \mathrm{MRC}$ Harwell Institute, Harwell OX11 ORD, UK

${ }^{17}$ Korea Mouse Phenotyping Center (KMPC), Seoul, Republic of Korea

${ }^{18}$ Department of Life Science, Ewha Womans University, Seoul, Repulic of Korea 
${ }^{19}$ Graduate School of Cancer Science and Policy, National Cancer Center, Gyeonggi, Republic of Korea

${ }^{20}$ Cambridge-Suda Genomic Resource Center, Medical College of Soochow University, Suzhou, 215123, China

${ }^{21}$ Institute of Experimental Genetics, Deutsches Forschungszentrum für Gesundheit und Umwelt (GmbH), Helmholtz Zentrum München, 85764 Neuherberg, Germany

${ }^{22}$ Institute of Developmental Genetics, Helmholtz Zentrum München, Deutsches

Forschungszentrum für Gesundheit und Umwelt (GmbH), 85764 Neuherberg, Germany

${ }^{23}$ Department of Molecular Physiology and Biophysics, Baylor College of Medicine, Houston, TX, USA, 77030

${ }^{24}$ Department of Molecular and Cellular Biology, Baylor College of Medicine, Houston, TX, USA, 77030

${ }^{25}$ TUM School of Life Sciences, Technische Universität München, 85354 Freising, Germany

${ }^{26}$ German Center for Diabetes Research (DZD), 85764 Neuherberg, Germany

${ }^{27}$ Department of Surgery, School of Medicine, University of California Davis, California, USA, 95618

${ }^{28}$ Laboratory of Developmental Biology and Genomics, BK21 Program Plus for Advanced Veterinary Science, Research Institute for Veterinary Science, College of Veterinary Medicine, Seoul National University, Seoul, Republic of Korea

${ }^{29}$ William Harvey Research Institute, Queen Mary University of London, London, EC1M 6BQ, UK ${ }^{30}$ Present address: Gempharmatech Co. Ltd, Nanjing, China 210061 
${ }^{31}$ Present address: MRC Integrative Epidemiology Unit, Bristol Medical School, University of

Bristol, UK

${ }^{32}$ Present address: Reproductive and Developmental Biology Laboratory, NIEHS, Research

Triangle Park, NC, USA, 27709

${ }^{33}$ Present address: Kymab LTD, The Bennet Building (B930), Babraham Research Campus,

Cambridge, UK

${ }^{34}$ Present address: The Jackson Laboratory for Genomic Medicine, Farmington, CT, USA, 06032 


\begin{abstract}
The International Mouse Phenotyping Consortium (IMPC) is generating and phenotyping null mutations for every protein-coding gene in the mouse ${ }^{1,2}$. The IMPC now uses Cas9, a programmable RNA-guided nuclease that has revolutionized mouse genome editing ${ }^{3}$ and increased capacity and flexibility to efficiently generate null alleles in the C57BL/6N strain. In addition to being a valuable novel and accessible research resource, the production of $>3,300$ knockout mouse lines using comparable protocols provides a rich dataset to analyze experimental and biological variables affecting in vivo null allele engineering with Cas9. Mouse line production has two critical steps - generation of founders with the desired allele and germline transmission (GLT) of that allele from founders to offspring. Our analysis identified that whether a gene is essential for viability was the primary factor influencing successful production of null alleles. Collectively, our findings provide best practice recommendations for generating null alleles in mice using Cas9; these recommendations may be applicable to other allele types and species.
\end{abstract}

\title{
Results \& Discussion
}

To produce the majority of its null alleles, the IMPC implemented a deletion strategy

(Supplemental Figure S1a) to remove a critical region (one or more exons shared by all annotated full-length transcripts) ${ }^{4}$ to cause a frameshift. Null alleles were primarily designed to introduce a frameshift in the first half of each gene's protein-coding sequence as this is predicted to cause full-length protein-coding transcripts to undergo nonsense-mediated decay ${ }^{5}$. While frameshifts can be achieved using single Cas9-mediated double-strand breaks repaired 
by non-homologous end joining to introduce small insertions or deletions (indels), exon

skipping during splicing can restore frame and partial allele function ${ }^{6-8}$. The deletion approach resembles the embryonic stem cell-based approaches used for decades to produce null alleles, albeit without selection cassette insertion. To evaluate experimental variables affecting mutant mouse production, we analysed data from 4,473 production attempts on 3,973 unique genes from eight different centres (Supplemental Table 1) recorded in the IMPC's international microinjection tracking system (iMITS; downloaded 2020 Oct 11 from https://www.idcc.org/imits/). Four experimental parameters were assessed for their effects on success: Cas9 delivery method, number of guide RNAs (gRNAs) used, deletion size, and number of founders selected for breeding, as well as changes to parameters on repeated production attempts.

Gene editing reagents were delivered by microinjection (pronuclear or cytoplasmic) ${ }^{9,10}$ or electroporation ${ }^{11-14}$ to target specific genes in C57BL/6N zygotes (Supplemental Figure S1b). Among unique gene production attempts (i.e. each gene represented only once; Supplemental Table 2), the founder rate, measured as the ratio of founders obtained to the number of embryos treated and transferred, was significantly higher using either cytoplasmic injection or electroporation compared to pronuclear injection of zygotes (Figure 1a; $p<2.22 \times 10^{-16}$, Wilcoxon rank sum test) with no difference between cytoplasmic injection and electroporation (Figure 1a; $p=0.26)$. When we excluded experiments from which no founders were produced, GLT rates by these three delivery methods were all greater than $95 \%(95.4 \%, 96.5 \%$ and $97.3 \%$, respectively) with no significant difference between them ( $p>0.15$ in pairwise comparisons with Pearson chi-square). 
Null deletion alleles were generated using Cas9 with guides flanking the critical region

(Supplemental Figure S1a). To mitigate the risk of a low activity or inactive Cas9-guide combination some experiments used four guides, two 5' and two $3^{\prime}$ flanking the target site.

There was no difference in founder rate production (Figure $\mathbf{1 b} ; \mathrm{p}=0.82$ Wilcoxon rank sum test) or GLT rates of genes edited with two or four guides (GLT 96.8\% and 95.7\%, respectively, $\mathrm{p}=0.096$ Pearson chi-square). Even with no apparent efficiency gain using additional guides, it is possible that some guides may perform better than others in vivo and that inactive or low activity guides may contribute to experimental failure. The use of two guides may reduce the risk, however small ${ }^{15-18}$ ), of off-target mutagenesis.

The size of the critical region excised to produce a null allele varied by gene. We partitioned the deletion size defined by the guides used into six bins with approximately equal numbers of deletion attempts and found no difference in founder rates $(p=0.34$, Kruskal-Wallis test for comparing medians of six groups; Figure $1 \mathrm{c})$ or GLT rates $(p=0.668$ Kruskal-Wallis test; data not shown) for deletion sizes below $1,400 \mathrm{bp}$. The relatively small number of attempts that would be present in bins above 1,400 bp precludes conclusive statistical analysis, however decreased efficiency with increased deletion size has been reported ${ }^{19}$.

We next assessed whether the number of founders bred affected GLT rate. These methods result in efficient germline editing and generating a single founder provided a $>95 \%$ chance of 
success. The overall high GLT rate was marginally improved by breeding up to three founders, but there was no apparent advantage to breeding more than three founders (Figure 1d).

While nearly $70 \%$ of first Cas9 production attempts were successful, it was unclear why $30 \%$ of Cas9 production attempts failed to produce GLT of the desired null allele. Many of these experiments were repeated (with or without changing parameters) and only $26.3 \%$ of second attempts and $16.5 \%$ of third attempts were successful (Figure 2a, Supplemental Table 3). We analysed the 403 sets of repeat attempts to determine what, if any, changes to experimental parameters improved success rates. Using a logistic regression model for GLT status conditional on experimental parameters, changing at least one guide sequence, irrespective of whether the critical region targeted changed, showed a statistically significant improvement in GLT rates (54\% with no change to guide sequence $c f .68 .8 \%$ with a changed guide sequence; Figure $\mathbf{2 b}$, Table 1). Changes to other parameters did not reveal any significant effect on success rates. While there was a significant decrease in success rates after the first attempt failed, changing the guide sequence improved the likelihood of repeated experiments generating the desired allele.

In considering biological variables that could influence founder and GLT rates, we hypothesized that targeting essential genes (genes whose function are necessary for the viability of cells or animals ${ }^{20}$ ) could negatively affect founder rates due to the high mutagenic efficiency of Cas9. In support of this, the founder rate obtained for cellular non-essential genes was significantly higher than for cellular essential genes ( $p<2 \times 10^{-16}$ Wilcoxon rank sum test; Figure $\left.3 a\right)$. This is 
echoed in the difference in founder rates amongst those genes that were assessed by the IMPC primary viability screen ${ }^{21}$ with genes that tested as homozygous lethal after production, so called "developmental essential" genes ${ }^{20}$, having a significantly lower founder rate than nonlethal genes ( $p=2.2 \times 10^{-11}$ Wilcoxon rank sum test; Figure $\left.3 b\right)$. Similarly, the birth rates for essential and lethal genes during founder production attempts were lower than that for nonessential and non-lethal genes (Supplemental Figure S2). This may reflect a loss of mutant embryos during gestation or shortly after birth due to effects of the introduced mutation. When repeated attempts were classified by gene essentiality $72.2 \%$ of first attempts were successful for cellular non-essential genes compared to $52.6 \%$ for cellular essential genes (Figure 3c). In addition, a larger percentage of cellular non-essential genes than essential genes were successful for each subsequent attempt, albeit with decreased success rates for each subsequent attempt for the same gene.

There was a small, but not statistically significant, difference in GLT rates between cellular nonessential and essential genes (96.8\% and 95.2\%, respectively; $p=0.15$ Pearson Chi-square) among experiments that generated founders. This may be a result of fewer founders obtained and therefore fewer bred for cellular essential genes compared to non-essential genes. Alternatively, this may occur when haplo-insufficient genes were targeted and produced mosaic founders that could not propagate mutant progeny that reached genotyping age.

To assess the influence of additional biological variables on founder and GLT rates, we applied a general linear model (GLM) to test the association of several factors including embryonic 
expression (GEO GSE11224) 22, observed/expected loss-of-function (o/e) and probability of lossof-function (pLI) scores ${ }^{23}$, chromosome position, histone methylation and acetylation (as a proxy for chromatin accessibility), cytogenic banding (a second proxy for chromatin accessibility), and OMIM annotation human orthologs ${ }^{24}$ (Supplemental Table 4). When gene essentiality was excluded from analysis, only embryonic expression was significantly associated with a low number of founders (odds ratio $(O R)=0.95, p=0.011$ ). However, when essentiality was included, it was the only predictor of experimental failure $\left(O R=0.89, p=2.06 \times 10^{-11}\right.$; Figure 3d, Table 2, Supplemental Table 5). The proportion of essential genes in each experimental parameter grouping did not vary in a way that may have confounded the results of those analyses (Supplemental Tables 6 and 7).

Once founders were obtained, GLT rates were very high (Figure 1d). Of the 74 genes for which the reason for GLT failure was ascertained, the founders from $\sim 18 \%$ of genes died before breeding and $\sim 43 \%$ of genes failed GLT due to founders not producing progeny or producing only wild-type progeny (Figure 4). The remaining genes failed primarily due to the inability to validate the desired null allele in N1 progeny (e.g., partial deletion or no frameshift recovered). Infertile founders and transmission of only wild-type progeny might be due to variable founder mosaicism with only wild-type cells contributing to the germline or able to produce functional germ cells. Moreover, transmission of only wild-type alleles could indicate the presence of haplo-insufficient alleles for some genes causing mutant progeny to die before genotyping. These data support the hypothesis that a substantial subset of mutations may fail GLT due to 
negative effects on viability or fertility and are consistent with the significant effect of gene essentiality on founder production (Table 2).

For quality control (QC) of mutant alleles, the IMPC requires sequence data with $\geq 100 \mathrm{bp}$ flanking DNA on both sides of the deletion junction. Alleles with deletions that do not result in frameshift mutations after sequencing fail QC. In a pilot study conducted at three production centres, the copy number of the deleted sequence in 6,653 N1 mice representing 703 uniquegene experiments was assessed. An extremely low rate of re-insertion of the deleted fragment distal to the deletion junction was detected (14/6,653 mice, $0.21 \%$, from $8 / 703$ genes, $1.1 \%$, data not shown). The founder screening methods employed by the IMPC explicitly exclude inversions, translocations, and deletions that extend more than several hundred base pairs from the targeted cut sites, all of which are known to occur after Cas9 treatment ${ }^{25-27}$. These types of alleles, while indicative of Cas9 activity, are not identified nor bred in the IMPC and are therefore part of the failed experimental group. Coupled with gene essentiality negatively impacting founder rate, the dataset analyzed herein was not appropriate for analysis of Cas9 activity.

As of October 2020, the IMPC has produced null alleles for 9,503 unique genes (this report and ${ }^{2}$ ), 4,182 of which were produced using Cas9 endonuclease (Figure 5a; Supplemental Table 8). Of the protein-coding genes with Cas9-derived alleles, 4,014 (96\%) have human orthologs and 2,729 (68\%) of these did not have non-IMPC alleles reported in MGI28 (Figure 5b). Collectively, the IMPC has contributed mouse lines and phenotyping data for 5,628 new 
protein-coding genes. Of the estimated 23,056 protein-coding genes in the mouse, $60 \%$

$(13,819)$ have targeted null alleles reported in MGI. All IMPC mouse lines are made available directly from the production centres and public repositories within the International Mouse Strain Resource ${ }^{29}$. The utility of these resources for the scientific community is demonstrated with $>900$ unique Cas9-derived mouse lines distributed to the world-wide scientific community. All IMPC mouse lines are phenotyped using the International Mouse Phenotyping Resource of Standardised Screens (IMPReSS) and the phenotyping data is freely available on the IMPC web portal $^{30}$. With accessible mouse lines enriched by comprehensive phenotyping data, the IMPC fills a critical resource gap in the biomedical community providing tools to identify disease gene candidates (e.g. ${ }^{20}$ ) and large-scale data sets to mine for gene-phenotype associations (e.g. ${ }^{31-33}$ ) and supporting hypothesis-driven research (e.g. ${ }^{34-37}$ ).

The analysis of our large, multi-centre dataset identified several variables that affect the success of Cas9 mutagenesis experiments and provides the basis for recommendations for genome editing in mouse zygotes. For deletion alleles, electroporation of Cas9 ribonucleoprotein (RNP) is the most accessible and scalable method, providing equivalent performance to cytoplasmic microinjection of Cas9 mRNA and gRNAs. GLT rates are high for Cas9 generated founders and there is no apparent advantage to breeding more than three founders. For attempts that fail to produce founders, changing guide sequences may be beneficial when repeating production for a given gene. The activity of particular Cas9-guide combinations can be assessed in vivo (e.g., by zygote treatment, in vitro culture, and blastocyst genotyping ${ }^{38}$ ). Exploring the known biology of the gene, such as predicted effects on 
bioRxiv preprint doi: https://doi.org/10.1101/2021.10.06.463037; this version posted October 6, 2021. The copyright holder for this preprint

(which was not certified by peer review) is the author/funder, who has granted bioRxiv a license to display the preprint in perpetuity. It is made available under aCC-BY-NC 4.0 International license.

phenotype (e.g., disease association of human ortholog), viability, and/or fertility as well as essentiality scores from publicly available sources (as in ${ }^{20}$ ), can inform whether conditional or other allele types may be preferred to a null allele. Overall, the use of Cas9 is a robust and flexible method for the generation of null allele mouse lines. Additional quality control including examining protein and RNA expression, can functionally validate alleles and elucidate mechanisms underlying observed phenotypes. Ongoing efforts at IMPC centres aim to complete null allele production and phenotyping for the mouse protein-coding genome over the coming years. 


\section{Materials \& Methods}

Mouse strains: All null allele mouse lines were produced in the C57BL/6N strain background available from Charles River, the Jackson Laboratory, Taconic, DBL (Korea), Envigo, NBRI (China) or CLEA Japan (Supplemental Methods Table 1). All live animal protocols conformed to the applicable standards for the ethical use of animals in research at the respective facilities with detailed ethics statements found in Supplemental Methods Table 1 for each production centre. Animal welfare was regularly monitored.

Allele design: Null alleles were designed such that the mutations resulting from Cas 9 endonuclease activity and double-strand break (DSB) repair caused a reading frameshift in protein-coding transcripts and introduced a premature stop codon. This required the identification of a critical region for each targeted gene. A critical region was defined as one or more exons that when frameshifted or deleted resulted in the open reading frames of all known full-length protein-coding transcripts (per Ensembl build 38) being out of frame ${ }^{4}$. For the majority of designs, the premature stop codon was predicted to be introduced in the first half of the protein-coding open reading frame and to target transcripts for nonsense-mediated decay $^{5,39}$. Such alleles are considered presumptive null alleles. Four major categories of alleles were generated. Indel alleles resulting from non-homologous end joining (NHEJ)-mediated repair of a single Cas9-induced DSB within the critical region of a gene. Exon deletion (exdel) alleles resulting from NHEJ-mediated repair of Cas9-induced DSBs flanking the exon(s) within a gene's critical region. Intra-exon deletion (intra-exdel) alleles resulting from repair of Cas9induced paired DSBs within a single exon in the target gene's critical region, used for example, when all exons of a gene are in the same frame so exon deletion would restore the reading 
frame or for single exon genes. Inter-exon deletion (inter-exdel) alleles resulting from repair of Cas9-induced paired DSBs in two or more different (often sequential) exons in a gene's critical region, used for example, to delete a functional domain that spans multiple exons or when introns were too small to allow an exdel allele design because specific gRNAs in appropriate locations cannot be identified. Indels and intra- and inter-exdel deletion alleles may be repaired such that the open reading frame is restored. Alleles that did not result in a frameshift failed quality control $(\mathrm{QC})$ metrics and were not maintained. Exceptions were made when the deletion was still in frame, but either removed critical protein domains (e.g., zinc fingers from a zinc-finger protein) or a substantial fraction of the protein-coding sequence; these alleles were also deemed to be presumptive null allele.

sgRNA selection; Guide RNA (gRNA) spacer sequences were selected using either the CRISPR design tool ${ }^{40}$, the Wellcome Sanger Genome Editing (WGE) Tool ${ }^{41}, \mathrm{CRISPOR}^{42}$, CRISPRTools $^{43}$, $\mathrm{CHOPCHOP}^{44}$, or FORCAST ${ }^{45}$. Suitable gRNA spacer sequences were selected to minimize predicted off-target mutagenesis using specificity scores $>65$ when available and/or sequences with at least 3 mismatches for all predicted off-target sites. For deletion alleles, multiple guides were used to generate deletion alleles, with either two, three, or four guides (2G, 3G, or 4G, respectively) with two or more guides flanking the target critical region. In the $3 G$ approach, the middle guide could be within an exon and result in the deletion in conjunction with either the upstream or downstream guide, removing either the splice acceptor or donor from the critical region, respective and resulting in mis-splicing and the introduction of a frameshift. Alternatively, if only the middle guide cut, a frameshift indel within the exon could be introduced. 
sgRNA synthesis: sgRNAs were synthesized by either subcloning sgRNA spacer sequences and in vitro transcription (plasmid-IVT), PCR and in vitro transcription (PCR-IVT) ${ }^{46}$, gBlock synthesis and in vitro transcription (gBlock-IVT), or by primer extension and in vitro transcription (PE-IVT) ${ }^{46}$ Alternatively, sgRNAs were purchased from commercial suppliers. See Supplemental Methods Table 1 for centre-specific reagent details.

PCR-IVT: DNA templates for PCR-IVT were produced using overlapping oligonucleotides in a high-fidelity PCR reaction ${ }^{47}$ or using a plasmid template (Addgene $\# 42230^{48}$ ) and appropriate primers $^{46}$. PCR amplicons were purified using the Monarch PCR \& DNA cleanup kit (New England BioLabs T1030) or the QIAQuick PCR purification kit (Qiagen 28104) and used as a template for in vitro transcription of the sgRNA with the T7 MEGAshortscript ${ }^{\mathrm{TM}}$ Kit (ThermoFisher AM1354).

Plasmid-IVT: Overlapping oligonucleotides with Bsal appendages to facilitate standard sticky ended cloning into a T7 expression plasmid (a kind gift from Sebastian Gerety, based upon ${ }^{49}$ ) were purchased annealed. Alternatively, annealed oligonucleotides were cloned into plasmid DR274 (Addgene \#4225050). Plasmid DNA was extracted using the QIAGEN Plasmid Plus 96 Kit (Qiagen 16181) and guide cloning confirmed by Sanger sequencing. The DNA was then linearized and used as a template for T7 RNA in vitro transcription using the T7 MEGAshortscript ${ }^{\mathrm{TM}}$ Kit (ThermoFisher AM1354) or Thermo T7 RNA polymerase (TOYOBO, TRL201).

gBlock-IVT: sgRNAs were synthesized directly from gBlock ${ }^{\circledR}$ DNA (IDT) templates containing the T7 promoter using the HiScribe ${ }^{\mathrm{TM}}$ T7 High Yield RNA Synthesis Kit (New England BioLabs E2050) following manufacturer's instructions for sgRNA synthesis. 
PE-IVT: The EnGen sgRNA Synthesis Kit (New England BioLabs E3322) was used for PE-IVT per the kit protocol, but with incubation at $37{ }^{\circ} \mathrm{C}$ for $60-90$ minutes prior to DNAse treatment. For some $3 \mathrm{G}$ and $4 \mathrm{G}$ designs, up to two primers (e.g. both upstream gRNAs or both downstream gRNAs) were pooled at appropriate final concentrations before PCR or PE-IVT. After in vitro transcription, RNA was purified using the RNA Clean \& Concentrator-25 (Zymo Research R1017) or the MEGAclear Transcription Clean-Up Kit (ThermoFisher AM1908). All samples were analyzed by Nanodrop to determine A260/280 and A260/230 ratios ( $\geq 1.9$ to pass quality control). The integrity and size of RNA was assessed by agarose gel electrophoresis, Agilent Bioanalyzer, Agilent RNA Tape or the Qiaxcel Advanced System (RNA QC V2.0). Synthesized sgRNAs were stored at $-80^{\circ} \mathrm{C}$ in elution buffer or stored as ammonium acetate precipitates in ethanol at $-20^{\circ} \mathrm{C}$. Before use, sgRNAs were either thawed on ice or pelleted, air dried, and resuspended in RNAse-free MI buffer.

Cas9: Cas9 mRNA was purchased (Supplemental Methods Table 1) or transcribed in-house ${ }^{51}$. Cas9 protein was purchased from commercial suppliers. See Supplemental Methods Table 1 for centre-specific reagent details.

Injection mix preparation: Injection mixes were prepared essentially as previously reported ${ }^{46}$ with or without filtration prior to injection. For mRNA microinjection, injection mixes consisted of Cas9 mRNA and sgRNA in microinjection buffer (Supplemental Methods Table 1). Concentrations for each production attempt are shown in Supplemental Table S7. For Cas9 protein microinjection, Cas9 ribnucleoprotein (RNP) complexes were produced by mixing the Cas9 protein with sgRNA at 5X the concentration shown in Supplemental Materials Table S1 in RNP injection buffer and incubating at $37^{\circ} \mathrm{C}$ or room temperature for 10 minutes. The RNP mix 
was then diluted with 4 volumes of RNP injection buffer prior to injection. See Supplemental

Methods Table 1 for centre-specific reagent details.

Electroporation mix preparation: Electroporation mixes were prepared essentially as

previously reported ${ }^{12-14,46}$. Electroporation mixes consisted of Cas9 protein and sgRNA in RNP electroporation buffer (Supplemental Methods Table 1) at $2 X$ the concentrations shown in Supplemental Table S7, incubated at 37으 or room temperature for 5-15 minutes, and placed on ice until electroporation. Immediately before electroporation, RNP was diluted with an equal volume of Opti-MEM (ThermoFisher 31985062). Alternatively, electroporation of Cas9 mRNA and sgRNAs was performed after dilution of RNAs in Opti-MEM. See Supplementary Methods Table 1 for centre-specific reagent details.

Generation of embryos by mating: C57BL/6N female mice, 3- 6 weeks old, were injected with 5 $\mathrm{IU} /$ mouse of pregnant mare serum, followed $46-48 \mathrm{hr}$ later with $5 \mathrm{IU} / \mathrm{mouse}$ of human chorionic gonadotropin. The females were then mated overnight with C57BL/6N males after the second injection. Fertilized oocytes were collected from females with copulatory plugs the following morning at $0.5 \mathrm{dpc}$. Oviducts were dissected and cumulus masses from these were released and treated with hyaluronidase. Fertilized 1-cell embryos were selected and maintained at $37^{\circ} \mathrm{C}$ in media prior to microinjection or electroporation.

Generation of embryos by IVF: In vitro fertilization was performed according to "IVF protocol using freshly harvested and frozen sperm (MBCD+GSH)" provided by Infrafrontier, https://www.infrafrontier.eu/knowledgebase/protocols/cryopreservation-protocols. C57BL/6N females, 8-10 weeks old, were used as oocyte donors and C57BL/6N males were used as sperm donors. 
Microinjection of CRISPR/Cas9 reagents: The number of embryos injected and the injection route (pronuclear or cytoplasmic) for each experiment is in Supplemental Table S7. Briefly, pronuclear microinjections were performed following standard protocols ${ }^{9,52}$. Cytoplasmic injections were performed essentially as in ${ }^{10}$. Visible movement of the cytoplasm indicated successful injection. Injected zygotes were transferred into pseudopregnant females (see Supplemental Methods Table 1) on the afternoon of the injection or after overnight culture (recorded for each production attempt in Supplemental Table S7), with 12-15 or 20-28 zygotes per unilateral or bilateral transfer into pseudopregnant females, respectively.

Electroporation of CRISPR/Cas9 reagents: Electroporation was performed essentially as previously described ${ }^{12-14,46}$. At some centres, zygotes were briefly treated with Acid Tyrode's solution (Sigma-Aldrich T1788). After acid treatment, embryos were rinsed at least 3 times with the final rinse in Opti-MEM. For electroporation, embryos were transferred into a 1:1 mixture of Cas9 RNP and Opti-MEM or Opti-MEM when RNP were formed in Opti-MEM. For each production attempt, electroporation pulses are in Supplemental Table S7. After electroporation the embryos were rinsed and transferred into pseudopregnant recipients the same day or after overnight culture (as recorded for each production attempt in Supplemental Table S7). Centre-specific details for buffers used are in Supplemental Methods Table 1. Genotyping: Genomic DNA was prepared from ear punch or tail biopsies of two- to three-weekold pups (see Supplemental Methods Table 1 for reagents) using commercial kits or previously described protocols ${ }^{53,54}$. DNA was amplified by standard end-point PCR or quantitative PCR (qPCR). End-point PCR assays were designed to produce differently sized amplicons. To detect wild-type alleles, one primer was designed outside of the deletion target sequence and the 
second primer designed within the deletion target sequence such that amplicons are only produced from wild-type alleles. To detect deletion alleles, primers were designed to flank the predicted deletion junction. Amplification can result in two amplicons - a shorter amplicon representing the deletion allele and a larger amplicon representing the wild-type allele, if PCR conditions allow the amplification of the larger amplicon. Three-primer designs use a common primer outside of the deletion for both amplicons. PCR products were visualized using the Caliper LabChip GX system, QIAxcel Advanced, or agarose gel electrophoresis. Indel alleles were identified by amplification of DNA followed by Sanger sequencing of the amplicon or $10 \%$ PAGE to identify changes in amplicon size. Primers were designed to be $\geq 150$-bp from the deletion junction or target cut site and sequences are available upon request from the relevant production centre.

In some cases, gene-specific 'loss of WT allele' (LoA) qPCR assays were designed to the region of the genome predicted to be deleted ${ }^{55,56}$. Deleted alleles will not amplify a product at the target site such that homozygous or hemizygous X-linked male deletions would have a copy number of 0 , heterozygous a copy number of 1 and mosaic animals a copy number between 1 and 2 for autosomal alleles or between 0 and 1 in hemizygous $\mathrm{X}$-linked alleles in males. These assays allowed estimation of the level of mosacism in founder animals. Mice showing the greatest loss of allele were selected for breeding to confirm germline transmission. Sequences for loss-ofallele assay primers and probes are available upon request from the relevant production centres. 
Once germline transmission was confirmed, mice were genotyped with either end-point PCR or probe-based LoA assays. Seep Supplemental Methods Table 1 for centre-specific genotyping methods.

Germline Transmission Test Breeding: Founders born from microinjection or electroporation experiments that carried the desired allele based on genotyping results were pair-mated to C57BL/6N mice. N1 pups were screened with the same end-point PCR genotyping assay used to identify founders. Deletion amplicons from mutation-positive N1 mice were subjected to Sanger sequencing (with or without subcloning) and other quality control measures as implemented from time to time.

Copy number assessment: To assess whether the excised genomic fragment from deletion alleles re-inserted into the genome, DNA from N1 mice was purified using the NucleoSpin Tissue Kit (Machery-Nagel 740453) and subjected to digital droplet PCR (ddPCR) at The Centre for Applied Genomics (Toronto, Canada) or at the Mouse Biology Program at the University of California, Davis. The ddPCR assays were designed such that the amplification primers and probes were entirely contained within the target deletion fragment. For heterozygous N1 mice, a copy number equal to 1 (+/-0.2) was considered a pass; for hemizygous X-linked male mice, a copy number equal to 0 was considered a pass.

Colony expansion and cohort production: One or more N1 mice from a single founder with identical allele sequences were used to expand colonies by backcrossing in pairs to C57BL/6N mice to generate $\mathrm{N} 2$ mice or by in vitro fertilization ${ }^{57}$ with C57BL/6N oocytes. Heterozygous N2 mice were either used for intercrossing to test viability (score number of born pups of each genotype, wild-type, heterozygous, homozygous) or to produce cohorts for phenotyping. If 
necessary, a further backcross using N2 mice and C57BL/6N wild-type mice was used to produce N3 mice and further expand the colony before intercrossing.

Data download and filtering: A complete data set of Cas9-mediated mouse production attempts was downloaded on October 11, 2020 from the International Microinjection Tracking System (iMITS; 'Cas9 Micro-Injection Excel download') used to record International Mouse Phenotyping Consortium (IMPC) data. This data included all Cas9-based production attempts. A production attempt was defined as the treatment of embryos to introduce Cas9 and guide RNAs to direct genome editing, subsequent embryo transfer, birth and screening of pups born from the embryo transfer, and subsequent breeding of mutant founders to obtain germline transmission of the desired edited allele. The data was filtered to remove attempts labeled as "private", as "experimental", or producing an allele other than a null allele, those with a status "Microinjection in Progress", embryo transfer day of "Next Day", none or $>1000$ embryos injected, incomplete information (e.g. number of founders not set, incomplete quality control information), and/or attempts that targeted non-protein coding genes. These data were further limited to attempts from production centres that had reported germline transmission for at least 50 unique genes for each of one or more of the analyzed methods (Cas9 mRNA pronuclear microinjection, Cas9 mRNA cytoplasmic injection, Cas9 RNP electroporation). This comprised the complete data set for analysis (Supplemental Table 8).

To define the set of unique gene experiments (i.e. each gene represented only once in the data set), the earliest attempt with germline transmission of the desired allele (Status = Genotype confirmed) for successful genes or the latest unsuccessful attempt (Status = Micro-injection aborted) was kept so that each gene was represented by a single attempt. If all attempts had a 
status of "Founder obtained", the most recent was kept. However, if none were successful in this filtered dataset, this could falsely give the impression that no successful knockout was produced by the IMPC using Cas9 for the gene. Thus, genes with a successful attempt in the pre-filtered dataset (e.g. at another production centre) were marked as such, but excluded from this analysis (Supplemental Table 2).

For repeat attempt analysis, all attempts at the same production centre for genes that had more than one attempt and whose first production attempt failed to produce a null mouse line were included. This data set was then filtered to remove attempts in progress (Status = "Microinjection in progress" or "Founders obtained"). The remaining attempts were sorted in chronological order by microinjection [electroporation] date and if the first attempt for a given gene was successful, the set of attempts for that gene at that Centre was removed. Similarly, if an attempt was aborted within 6 weeks of a successful germline transmission attempt, it was removed since it may have been aborted because germline transmission had already been obtained, rather than having "failed". Finally, if there was no GLT in any attempt at one centre, but successful GLT at another centre, it was removed from the repeat dataset. The resulting data set comprised the repeat dataset (Supplemental Table 3).

The set of non-IMPC produced mouse null alleles, including conditional-ready null alleles and reporter alleles, was obtained from Mouse Genome Informatics as in Birling et al. ${ }^{2}$.

The complete production data set including attempts to produce both ES cell- and Cas9-derived mouse lines, was downloaded from iMITS (All Microinjection Attempts) on October 2, 2020.

This data set was limited to all successful production attempts (Status = Genotype confirmed). The successful attempts were then filtered to remove experiments in strain backgrounds other 
than $\mathrm{C} 57 \mathrm{BL} / 6 \mathrm{~N}$, that targeted non-protein coding genes, or that were designed to generate alleles other than a null allele. The data set was then sorted by gene and genotype confirmed date and the first successful production attempt for each gene was kept (Supplemental Table 8). These successful attempts were then plotted against time or compared to null mouse lines produced by other scientists or consortia registered in MGI (Figure 5).

Data Annotation: Genes targeted for mouse line production attempts in Supplemental Table 2 were annotated with derived parameters including bins for mRNA and protein concentration, gRNA cut sites and predicted deletion sizes, percentage of embryos that survived to transfer of those treated (injected or electroporated), birth rate (number of pups born divided by embryos transferred), founder rate (number of founders born divided by embryos transferred), ratio of founders selected for breeding (number of founders bred divided by number of founders).

Repeat attempts (Supplemental Table 3) were annotated with whether the Cas9 type (mRNA vs. protein), amount of Cas9, delivery of reagents (injection versus electroporation), or gRNA locations changed between sequential attempts. All filtering and annotation of the data was performed in Python3.8.5 using packages numPy1.2.1 $1^{58}$ and pandas1.2.2 $2^{59}$.

Genes for each attempt were annotated (Supplemental Table 4) with their viability (as annotated at the IMPC - viable or homozygous lethal), human orthologs and cell essentiality of human orthologous genes ${ }^{20}$, embryonic expression (GEO GSE11224) ${ }^{22}$, length, GC content, number of CpG sites, and CpG percentage (Supplemental Methods Table 2). The human orthologs' probability of being loss-of-function intolerant (pLI) and observed / expected (oe) mutation rate was retrieved from gnomAD ${ }^{23}$. Annotation details are in Supplemental Methods 
Table 2. Additional annotations were added for analysis of biological variables affecting success as described in Supplemental Methods Table 3.

Statistical Analysis: The primary outcomes were the founder rate and the germline transmission status. The founder rate had a right-skewed distribution with a range $[0,0.5]$. Hence, comparisons of the founder rate across different categories of biological or experimental factors were conducted using nonparametric tests. For pairwise comparisons, the Wilcoxon rank sum test ${ }^{60}$ was used and when there were more than two categories the KruskalWallis test ${ }^{61}$ was employed. The biological factors considered in the comparisons were the gene essentiality (essential versus non-essential) and gene lethality (lethal versus non-lethal). The experimental factors were the delivery method (three categories), number of gRNAs used ( 2 versus 4), deletion size (six categories), and number of founders selected for breeding (four categories). Since the GLT status is binary (yes versus no), comparisons of the GLT rate (proportion of genes with GLT) across different categories of biological or experimental factors were performed using the Pearson chi-square test ${ }^{62}$. In the case of multiple pairwise comparisons, correction for multiple testing was done using Holm's method ${ }^{63}$. Evaluation of success of repeated attempts was based on descriptive summaries, mainly calculation of relevant proportions. The assessment of the impact of changing experimental factors to the success of gene editing in repeated attempts was conducted using logistic regression with the GLT status as the binary response and changes in the delivery method (change versus no change), number of gRNAs used (decrease, no change, increase), deletion size (change versus no change) and number of founders selected for breeding (change versus no change) as categorical covariates. All statistical analyses were performed using the R statistical programing 
software ${ }^{64}$, along with the packages ggplot $2^{65}$ for figures, tidyverse ${ }^{66}$ for data

manipulations and effects ${ }^{67,68}$ for effect plots.

The general linear models of biological variables were fit using the glm function in the R 3.6.2 native stats package (https://rdocumentation.org/packages/stats/versions/3.6.2) using the factors in Supplemental Methods Table 4 and with founder rate as the dependent variable. All code can be found at https://github.com/The-Centre-for-Phenogenomics/IMPC-Cas9-

Production. 


\section{[References]}

1 Lloyd, K. C. K. et al. The Deep Genome Project. Genome Biol 21, 18, doi:10.1186/s13059020-1931-9 (2020).

2 Birling, M. C. et al. A resource of targeted mutant mouse lines for 5,061 genes. Nat Genet 53, 416-419, doi:10.1038/s41588-021-00825-y (2021).

3 Wang, H. et al. One-step generation of mice carrying mutations in multiple genes by CRISPR/Cas-mediated genome engineering. Cell 153, 910-918, doi:10.1016/j.cell.2013.04.025 (2013).

4 Bradley, A. et al. The mammalian gene function resource: the international knockout mouse consortium. Mamm Genome 23, 580-586, doi:10.1007/s00335-012-9422-2 (2012).

5 Popp, M. W. \& Maquat, L. E. The dharma of nonsense-mediated mRNA decay in mammalian cells. Mol Cells 37, 1-8, doi:10.14348/molcells.2014.2193 (2014).

6 Smits, A. H. et al. Biological plasticity rescues target activity in CRISPR knock outs. Nat Methods 16, 1087-1093, doi:10.1038/s41592-019-0614-5 (2019).

7 Lalonde, S. et al. Frameshift indels introduced by genome editing can lead to in-frame exon skipping. PLoS One 12, e0178700, doi:10.1371/journal.pone.0178700 (2017).

8 Mou, H. et al. CRISPR/Cas9-mediated genome editing induces exon skipping by alternative splicing or exon deletion. Genome Biol 18, 108, doi:10.1186/s13059-017-1237-8 (2017).

9 Behringer, R. R., Gertsenstein, M., Nagy, K. \& Nagy, A. Manipulating the Mouse Embryo: A Laboratory Manual. 4th edn, (Cold Spring Harbor Laboratory Press, 2014). 
10 Doe, B., Brown, E. \& Boroviak, K. Generating CRISPR/Cas9-Derived Mutant Mice by Zygote Cytoplasmic Injection Using an Automatic Microinjector. Methods Protoc 1, doi:10.3390/mps1010005 (2018).

11 Gertsenstein, M. \& Nutter, L. M. J. Production of knockout mouse lines with Cas9. Methods 191, 32-43, doi:10.1016/j.ymeth.2021.01.005 (2021).

12 Wang, W. et al. Delivery of Cas9 Protein into Mouse Zygotes through a Series of Electroporation Dramatically Increases the Efficiency of Model Creation. Journal of genetics and genomics = Yi chuan xue bao 43, 319-327, doi:10.1016/j.jgg.2016.02.004 (2016).

13 Kaneko, T., Sakuma, T., Yamamoto, T. \& Mashimo, T. Simple knockout by electroporation of engineered endonucleases into intact rat embryos. Scientific reports 4, 6382, doi:10.1038/srep06382 (2014).

14 Modzelewski, A. J. et al. Efficient mouse genome engineering by CRISPR-EZ technology. Nat Protoc 13, 1253-1274, doi:10.1038/nprot.2018.012 (2018).

15 Peterson, K. A. et al. Whole genome analysis for 163 guide RNAs in Cas9 edited mice reveals minimal off-target activity. BioRxiv doi:10.1101/2021.08.11.455876 (2021).

16 lyer, V. et al. Off-target mutations are rare in Cas9-modified mice. Nat Methods 12, 479, doi:10.1038/nmeth.3408 (2015).

17 Anderson, K. R. et al. CRISPR off-target analysis in genetically engineered rats and mice. Nat Methods 15, 512-514, doi:10.1038/s41592-018-0011-5 (2018).

18 Willi, M., Smith, H. E., Wang, C., Liu, C. \& Hennighausen, L. Mutation frequency is not increased in CRISPR-Cas9-edited mice. Nat Methods 15, 756-758, doi:10.1038/s41592-0180148-2 (2018). 
19 Lanza, D. G. et al. Comparative analysis of single-stranded DNA donors to generate conditional null mouse alleles. BMC biology 16, 69, doi:10.1186/s12915-018-0529-0 (2018).

20 Cacheiro, P. et al. Human and mouse essentiality screens as a resource for disease gene discovery. Nature communications 11, 655, doi:10.1038/s41467-020-14284-2 (2020).

21 Ring, N. et al. A mouse informatics platform for phenotypic and translational discovery. Mamm Genome 26, 413-421, doi:10.1007/s00335-015-9599-2 (2015).

22 Barrett, T. et al. NCBI GEO: archive for functional genomics data sets--update. Nucleic Acids Res 41, D991-995, doi:10.1093/nar/gks1193 (2013).

23 Karczewski, K. J. et al. The mutational constraint spectrum quantified from variation in 141,456 humans. Nature 581, 434-443, doi:10.1038/s41586-020-2308-7 (2020).

24 Online Mendelian Inheritance in Man, $\mathrm{OMIM}^{\circledR}$. McKusick-Nathans Institute of Genetic Medicine, Johns Hopkins University (Baltimore, MD), URL: https://omim.org (2020).

25 Boroviak, K., Fu, B., Yang, F., Doe, B. \& Bradley, A. Revealing hidden complexities of genomic rearrangements generated with Cas9. Scientific reports 7, 12867, doi:10.1038/s41598-017-12740-6 (2017).

26 Kosicki, M., Tomberg, K. \& Bradley, A. Repair of double-strand breaks induced by CRISPRCas9 leads to large deletions and complex rearrangements. Nat Biotechnol 36, 765-771, doi:10.1038/nbt.4192 (2018).

27 Kosicki, M., Tomberg, K. \& Bradley, A. Erratum: Repair of double-strand breaks induced by CRISPR-Cas9 leads to large deletions and complex rearrangements. Nat Biotechnol 36, 899, doi:10.1038/nbt0918-899c (2018). 
28 Eppig, J. T. et al. Mouse Genome Informatics (MGI): reflecting on 25 years. Mamm Genome 26, 272-284, doi:10.1007/s00335-015-9589-4 (2015).

29 Eppig, J. T., Motenko, H., Richardson, J. E., Richards-Smith, B. \& Smith, C. L. The International Mouse Strain Resource (IMSR): cataloging worldwide mouse and ES cell line resources. Mamm Genome 26, 448-455, doi:10.1007/s00335-015-9600-0 (2015).

30 Koscielny, G. et al. The International Mouse Phenotyping Consortium Web Portal, a unified point of access for knockout mice and related phenotyping data. Nucleic Acids Res 42, D802-809, doi:10.1093/nar/gkt977 (2014).

31 Bowl, M. R. et al. A large scale hearing loss screen reveals an extensive unexplored genetic landscape for auditory dysfunction. Nature communications 8, 886, doi:10.1038/s41467017-00595-4 (2017).

32 Rozman, J. et al. Identification of genetic elements in metabolism by high-throughput mouse phenotyping. Nature communications 9, 288, doi:10.1038/s41467-017-01995-2 (2018).

33 Moore, B. A. et al. Identification of genes required for eye development by highthroughput screening of mouse knockouts. Commun Biol 1, 236, doi:10.1038/s42003-0180226-0 (2018).

34 Stroup, B. M. et al. A global Slc7a7 knockout mouse model demonstrates characteristic phenotypes of human lysinuric protein intolerance. Hum Mol Genet 29, 2171-2184, doi:10.1093/hmg/ddaa107 (2020).

35 Mahgoub, M. et al. Dual histone methyl reader ZCWPW1 facilitates repair of meiotic double strand breaks in male mice. eLife 9, doi:10.7554/eLife.53360 (2020). 
36 Bryant, D. et al. Diverse species-specific phenotypic consequences of loss of function sorting nexin 14 mutations. Scientific reports 10, 13763, doi:10.1038/s41598-020-70797-2 (2020).

37 Burrage, L. C. et al. Bi-allelic Variants in TONSL Cause SPONASTRIME Dysplasia and a Spectrum of Skeletal Dysplasia Phenotypes. American journal of human genetics 104, 422438, doi:10.1016/j.ajhg.2019.01.007 (2019).

38 Scavizzi, F. et al. Blastocyst genotyping for quality control of mouse mutant archives: an ethical and economical approach. Transgenic Res 24, 921-927, doi:10.1007/s11248-0159897-1 (2015).

39 Popp, M. W. \& Maquat, L. E. Organizing principles of mammalian nonsense-mediated mRNA decay. Annu Rev Genet 47, 139-165, doi:10.1146/annurev-genet-111212-133424 (2013).

40 Ran, F. A. et al. Genome engineering using the CRISPR-Cas9 system. Nat Protoc 8, 22812308, doi:10.1038/nprot.2013.143 (2013).

41 Hodgkins, A. et al. WGE: a CRISPR database for genome engineering. Bioinformatics 31, 3078-3080, doi:10.1093/bioinformatics/btv308 (2015).

42 Haeussler, M. et al. Evaluation of off-target and on-target scoring algorithms and integration into the guide RNA selection tool CRISPOR. Genome Biol 17, 148, doi:10.1186/s13059-016-1012-2 (2016).

43 Peterson, K. A. et al. CRISPRtools: a flexible computational platform for performing CRISPR/Cas9 experiments in the mouse. Mamm Genome 28, 283-290, doi:10.1007/s00335017-9681-z (2017). 
44 Labun, K., Montague, T. G., Gagnon, J. A., Thyme, S. B. \& Valen, E. CHOPCHOP v2: a web tool for the next generation of CRISPR genome engineering. Nucleic Acids Res 44, W272276, doi:10.1093/nar/gkw398 (2016).

45 Elrick, H. et al. FORCAST: a fully integrated and open source pipeline to design Casmediated mutagenesis experiments. bioRxiv, doi:10.1101/2020.04.21.053090 (2020).

46 Gertsenstein, M. \& Nutter, L. M. J. Engineering point mutant and epitope-tagged alleles in mice using Cas9 RNA-guided nuclease. Curr Protoc Mouse Biol 8, 28-53, doi:10.1002/cpmo.40 (2018).

47 Bassett, A. R., Tibbit, C., Ponting, C. P. \& Liu, J. L. Highly efficient targeted mutagenesis of Drosophila with the CRISPR/Cas9 system. Cell reports 4, 220-228, doi:10.1016/j.celrep.2013.06.020 (2013).

48 Cong, L. et al. Multiplex genome engineering using CRISPR/Cas systems. Science 339, 819823, doi:10.1126/science.1231143 (2013).

49 Mali, P. et al. RNA-guided human genome engineering via Cas9. Science 339, 823-826, doi:10.1126/science.1232033 (2013).

50 Hwang, W. Y. et al. Efficient genome editing in zebrafish using a CRISPR-Cas system. Nat Biotechnol 31, 227-229, doi:10.1038/nbt.2501 (2013).

51 Mianne, J. et al. Correction of the auditory phenotype in C57BL/6N mice via CRISPR/Cas9mediated homology directed repair. Genome Med 8, 16, doi:10.1186/s13073-016-0273-4 (2016).

52 Gardiner, W. J. \& Teboul, L. Overexpression transgenesis in mouse: pronuclear injection. Methods Mol Biol 561, 111-126, doi:10.1007/978-1-60327-019-9_8 (2009). 
53 Truett, G. E. et al. Preparation of PCR-quality mouse genomic DNA with hot sodium hydroxide and tris (HotSHOT). Biotechniques 29, 52, 54, doi:10.2144/00291bm09 (2000).

54 Green, M. R. \& Sambrook, J. Molecular Cloning: A Laboratory Manual. Vol. 3 (Cold Spring Harbor Laboratory Press, 2012).

55 Ryder, E. et al. Molecular characterization of mutant mouse strains generated from the EUCOMM/KOMP-CSD ES cell resource. Mamm Genome 24, 286-294, doi:10.1007/s00335013-9467-x (2013).

56 Mianne, J. et al. Analysing the outcome of CRISPR-aided genome editing in embryos: Screening, genotyping and quality control. Methods 121-122, 68-76, doi:10.1016/j.ymeth.2017.03.016 (2017).

57 Hasegawa, A. et al. Efficient production of offspring from Japanese wild-derived strains of mice (Mus musculus molossinus) by improved assisted reproductive technologies. Biol Reprod 86, 167, 161-167, doi:10.1095/biolreprod.111.098491 (2012).

58 Harris, C. R. et al. Array programming with NumPy. Nature 585, 357-362, doi:10.1038/s41586-020-2649-2 (2020).

59 McKinney, W. in 9th Python in Science Conference. (eds S. van der Walt \& J. Millman) 50-61.

60 Wilcoxon, F. Individual comparisons by ranking methods. Biometrics Bulletin 1, 80-83, doi:10.2307/3001968 (1945).

61 Kruskal, W. H. \& Wallis, W. A. Use of Ranks in One-Criterion Variance Analysis. Journal of the American Statistical Association 47, 583-621, doi:10.1080/01621459.1952.10483441 (1952). 
62 Pearson, K. X. On the criterion that a given system of deviations from the probable in the case of a correlated system of variables is such that it can be reasonably supposed to have arisen from random sampling. The London, Edinburgh, and Dublin Philosophical Magazine and Journal of Science 50, 157-175, doi:10.1080/14786440009463897 (1900).

63 Holm, S. A Simple Sequentially Rejective Multiple Test Procedure. Scandinavian Journal of Statistics 6, 65-70, doi:10.2307/4615733 (1979).

64 R Core Team. R: A language and environment for statistical computing. R Foundation for Statistical Computing, URL https://www.R-project.org/ (Vienna, Austria, 2021).

65 Wickham, H. ggplot2: Elegant Graphics for Data Analysis. https://ggplot2.tidyverse.org (Springer-Verlag, 2016).

66 Wickham, H. et al. Welcome to the Tidyverse. The Journal of Open Source Software 4, 1686, doi:10.21105/joss.01686 (2019).

67 Fox, J. Effect Displays in R for Generalised Linear Models. 2003 8, 27, doi:10.18637/jss.v008.i15 (2003).

68 Fox, J. \& Weisberg, S. An R companion to applied regression. Third edition edn, (SAGE, 2019).

\section{[Author contributions]}

K.A.P., D.G.L., L.T., S.A., M-C. B., F.C., G.F.C., G.D., L.O.G., C.J., P.K., D.A., H.L., L.G.L., Z.L., I.L., M.M., S.M., M.R., C.S., B.J.W., J. Zhang, F.Z., J.D.H., and L.M.J.N. designed alleles; J.A.W., D.G.L., E.J.R., S.A., A.C., F.C., G.F.C., B.D., G.D., A.G., M.G., L.O.G., P.K., D.P., H.L., L.G.L., Z.L., M.M., S.M., H.W-J., B.J.W., J. Zhang, F.Z., K.C.K.L., S.A.M., and L.M.J.N. produced mouse lines or data; H.E., 
A.G-S., R.E.K., P.M., and L.S. developed software, databases and/or reporting tools; H.E., K.A.P.,

E.F.A., R.E.K., S.A.M., and L.M.J.N. analyzed data for the figures in the manuscript; J.A.W.,

D.G.L., L.T., M-C.B., A.C., F.C., L.O.G., P.K., H.L., I.L., M.M., L.S., J.R.S., B.A.W., J. Zhao, D.J.A., A.B.,

R.E.B., F.J.D., M.E.D., X.G., Y.H. M.H.A., K.C.K.L., A-M. M., F.M., C.M., T.M., H.P., R.R-S., R.S.,

J.K.S., W.C.S., D.M., M.T., S.W., J.K.W., W.W., A.Y., S.A.M., J.D.H., and L.M.J.N. co-supervised

research; H.E., E.F.A., and L.M.J.N. wrote the manuscript. All authors reviewed and had the opportunity to comment on and edit the manuscript before submission.

\section{[Acknowledgements]}

We thank all technical personnel at the IMPC production centres for their contributions. H.E., E.F.A., M.G., L.G.L., and L.M.J.N. were supported by Ontario Genomics and Genome Canada OGI-051, OGI-090, OGI-137 and the Canada Foundation for Innovation. S.A., M.T., and A.Y. were supported by the National BioResource Project of Ministry of Education, Culture, Sports, Science and Technology (MEXT), Japan. M-C.B. and Y.H. were supported by the Université de Strasbourg, the CNRS, the INSERM and the 'Investissements d'avenir' programs (ANR-10-IDEX0002-02, ANR-10-LABX-0030-INRT and ANR-10-INBS-07 PHENOMIN). A.C., G.F.C., M.M., L.T., and S.W. were supported by the Medical Research Council IMPC Strategic Award (53658). F.C., A.G., and F.M. were supported by Attività internazionale afferente all'area di MonterotondoIBCN/MIUR: DSB.AD008.052.001. B.D., G.D., E.J.R., H. W.-J., D.A., A.B., R. R.-S., and W.C.S. were supported by the Wellcome Trust. A.G.S., P.M., T.M., and H.P. were supported by European Molecular Biology Laboratory core funding. P.K. and R.S. used services of the Czech Centre for Phenogenomics supported by the Czech Academy of Sciences RVO 68378050 and project 
LM2018126 Czech Centre for Phenogenomics provided by Ministry of Education, Youth and Sports of the Czech Republic, LM2015040 Czech Centre for Phenogenomics by MEYS,

CZ.1.05/2.1.00/19.0395 Higher quality and capacity for transgenic models by MEYS and ERDF,

CZ.1.05/1.1.00/02.0109 Biotechnology and Biomedicine Centre of the Academy of Sciences and Charles University in Vestec (BIOCEV) by MEYS and ERDF, CZ.02.1.01/0.0/0.0/16_013/0001789 Upgrade of the Czech Centre for Phenogenomics by MEYS and ESIF. Z.L., J.Zhang, and F.Z. were supported by grants from the Ministry of Science and Technology (2018YFA0801100), Science and Technology Project of Jiangsu Province (BZ2020067). S.M., C.S., M.H.A., and W.W. were supported by European Commission EUCOMM (EU-FP6, LSHM-CT-2005-01893), by Infrafrontier 01KX1012 (M.H.A.), German Center for Diabetes Research (M.H.A.), EU Horizon 2020: IPAD-MD GA-No. 653961 (M.H.A.), and INFRAFRONTIER2020 GA-No. 730879 (M.H.A.). D.L., H.L., and J.K.S. were supported by the National Research Foundation (NRF) \& funded by the Korean government (MSIT) (2013M3A9D5072550, 2014M3A9D5A01075128, and 2014M3A9D5A01074636).

Research reported in this publication was supported by the NIH Common Fund, the Office of The Director and the National Human Genomic Research Institute of the National Institutes of Health (U42OD011174 and UMIHG006348 supported A.C., G.F.C., F.J.D., I.L., M.M., J.R.S., L.T., S.W., M.E.D., and J.D.H.; U42OD011175 and UM1OD023221 supported M.G., L.G.L., C.M., L.M.J.N., B.J.W., J.A.W., M.R., and K.C.L.; U42OD011185 and UM1OD023222 supported L.O.G., K.A.P., R.E.B., J.K.W., and S.A.M.; UM1HG006370 supported A.G.-S., R.E.K., P.M., T.M., L.S., A.M.M., and H.P.). The content is solely the responsibility of the authors and does not necessarily represent the official views of the National Institutes of Health. 


\section{International Mouse Phenotyping Consortium (IMPC)}

Shaheen Akhtar ${ }^{9}$, Alasdair J. Allan ${ }^{8}$, Susan Allen ${ }^{8}$, Philippe André $^{11}$, Daniel Archer $^{8}$, Sarah Atkins ${ }^{8}$,

Ruth Avery ${ }^{8}$, Abdel Ayadi $^{11}$, Daniel Barrett ${ }^{9}$, Tanya Beyetinova $^{9}$, Toni Bell ${ }^{8}$, Rey Bernhard ${ }^{21}$,

Melissa Berry ${ }^{3}$, Katharina Boroviak ${ }^{9}$, Joanna Bottomley ${ }^{9}$, Tim Brendler-Spaeth $^{9}$, Ellen Brown ${ }^{9}$,

Jonathan Burvill ${ }^{9}$, James Bussell ${ }^{9}$, Charis Cardeno ${ }^{4}$, Rebecca V. Carter ${ }^{9}$, Patricia Castellanos-

Penton $^{1,2}$, Tsz Kwan Cheng ${ }^{16}$, Skevoulla Christou ${ }^{8}$, Greg Clark ${ }^{1,2}$, Shannon Clarke ${ }^{1,2}$, James Cleak $^{8}$,

Ronnie Crawford ${ }^{9}$, Amie Creighton ${ }^{1,2}$, Maribelle Cruz $^{1}$, Ozge Danisment ${ }^{1,2}$, Phuong Dao ${ }^{4}$,

Charlotte Davis $^{8}$, Daniel Delbarre ${ }^{16}$, Joanne Doran $^{9}$, Valérie Erbs $^{11}$, Qing Fan-Lan ${ }^{1,2}$, Rachel Fell ${ }^{8}$,

Giesert Florian ${ }^{21}$, Jean-Victor Fougerolle ${ }^{11}$, Alex Fower ${ }^{8}$, Gemma Frake $^{8}$, Martin D. Fray ${ }^{8}$,

Antonella Galli ${ }^{9}$, David Gannon ${ }^{9}$, Wendy J. Gardiner ${ }^{8}$, Angelina Gaspero ${ }^{5}$, Diane Gleeson ${ }^{9}$, Chris

Godbehere $^{8}$, Evelyn Grau ${ }^{9}$, Nina D. Griffith ${ }^{5}$, Mark Griffiths ${ }^{9}$, Nicola Griggs ${ }^{9}$, Kristin Grimsrud ${ }^{4}$,

Sarah Hazeltine ${ }^{4}$, Denise Herold ${ }^{21}$, Marie Hutchison ${ }^{8}$, Catherine Ingle $^{9}$, Mizuho Iwama ${ }^{10}$, Vivek

Iyer $^{9}$, Kayla Jager ${ }^{4}$, Joanna Joeng ${ }^{1,2}$, Susan Kales ${ }^{3}$, Perminder Kaur ${ }^{4}$, Janet Kenyon ${ }^{8}$, Piia Keskivali-

Bond $^{16}$, Kyoungmi Kim ${ }^{17}$, Jana Kopkanova ${ }^{15}$, Christelle Kujath ${ }^{11}$, Helen Kundi ${ }^{9}$, Peter Kutny ${ }^{3}$,

Valerie Laurin ${ }^{1,2}$, Young Jae Lee ${ }^{17}$, Sandrine Lejeay ${ }^{11}$, Christopher Lelliott ${ }^{9}$, Jorik Loeffler ${ }^{8}$,

Romain Lorentz ${ }^{11}$, Christopher V. McCabe ${ }^{8}$, Elke Malzer ${ }^{8}$, Hiroshi Masuya $^{10}$, Ryea Maswood ${ }^{9}$,

Matthew McKay ${ }^{3}$, David Melvin ${ }^{9}$, Saori Mizuno-lijima ${ }^{10}$, Alison Murphy ${ }^{9}$, Toshiaki Nakashiba ${ }^{10}$,

Kenichi Nakashima ${ }^{10}$, Hatsumi Nakata ${ }^{10}$, Asif Nakhuda ${ }^{9}$, Yuichi Obata ${ }^{10}$, Miriam Pasquini ${ }^{12}$, Amit

Patel $^{1}$, Ilya Paulavets ${ }^{9}$, Guillaume Pavlovic ${ }^{11}$, Fran J. Pike ${ }^{8}$, Radka Platte ${ }^{9}$, Peter D. Price ${ }^{8}$,

Marcello Raspa ${ }^{12}$, Shalini Reddy ${ }^{9}$, Markus Romberger ${ }^{21}$, Barry Rosen ${ }^{9}$, Victoria Ross ${ }^{9}$, Isobel

Russell $^{16}$, Ferdinando Scavizzi ${ }^{12}$, Laurence Schaeffer ${ }^{11}$, Alix Schwiening ${ }^{9}$, Mohammed Selloum ${ }^{11}$, 
Debarati Sethi ${ }^{9}$, Toshihiko Shiroishi ${ }^{10}$, Jan R. Sidiangco ${ }^{8}$, Caroline Sinclair $^{9}$, Elodie Sins ${ }^{9}$, Gillian Sleep ${ }^{1,2}$, Tania Sorg ${ }^{11}$, Becky Starbuck $^{8}$, Michelle Stewart $^{8}$, Young Hoon Sung $^{17}$, Holly Swash ${ }^{8}$, Mark Thomas ${ }^{9}$, Sandra Tondat ${ }^{1}$, Rachel Urban ${ }^{3}$, Jana Urbanova ${ }^{9}$, Bora Vardal ${ }^{16}$, Susan Varley ${ }^{8}$, Dominque Von Schiller ${ }^{9}$, Lauren Weavers ${ }^{9}$, Henrik Westerberg ${ }^{16}$, Michael Woods $^{9}$, Xu Ying $^{20}$, Melinda Zmerzlikar ${ }^{4}$ 
Table 1. Logistical regression model for GLT status between production attempts conditional on experimental parameters

\begin{tabular}{lccc}
\hline Predictors & Odds Ratio & $\mathrm{Cl}$ & $\mathrm{p}$-value \\
\hline (Intercept) & 1.18 & $0.96-1.47$ & 0.136 \\
$\Delta$ Delivery method & 0.74 & $0.45-1.21$ & 0.222 \\
$\Delta$ Decrease no. guides & 1.88 & $0.92-4.07$ & 0.092 \\
$\Delta$ Increase no. guides & 0.86 & $0.37-2.03$ & 0.731 \\
$\Delta$ Guide sequence & 1.88 & $1.02-3.58$ & 0.048 \\
$\Delta$ Target exon & 1.22 & $0.44-3.58$ & 0.709 \\
\hline
\end{tabular}

Observations: 498

Table 2. General linear model for successful production of founders conditional on biological factors annotated for a gene

\begin{tabular}{lcccc}
\hline Variable & \multicolumn{2}{c}{ Without Essentiality } & \multicolumn{2}{c}{ With Essentiality } \\
\hline & Odds Ratio & p-value & Odds Ratio & -value \\
\hline (Intercept) & 2.50 & $2.0 \times 10^{-16}$ & 2.52 & $2.22 \times 10^{-16}$ \\
Essential & $\mathrm{NA}$ & $\mathrm{NA}$ & 0.89 & $2.06 \times 10^{-11}$ \\
Embryonic expression & 0.95 & 0.011 & 0.97 & 0.219 \\
pLI score & 0.97 & 0.101 & 0.97 & 0.183 \\
o/e score & 1.00 & 0.987 & 1.00 & 0.887 \\
Chromosome position & 1.01 & 0.647 & 1.01 & 0.653 \\
Acetylated gene & 0.98 & 0.193 & 0.99 & 0.450 \\
Methylated gene & 1.03 & 0.137 & 1.01 & 0.383 \\
Gram positive stain & 1.00 & 0.938 & 1.00 & 0.891 \\
OMIM annotation & 0.99 & 0.412 & 0.98 & 0.220 \\
\hline
\end{tabular}

Observations: 3209 
bioRxiv preprint doi: https://doi.org/10.1101/2021.10.06.463037; this version posted October 6, 2021. The copyright holder for this preprint (which was not certified by peer review) is the author/funder, who has granted bioRxiv a license to display the preprint in perpetuity. It is made available under aCC-BY-NC 4.0 International license.

a

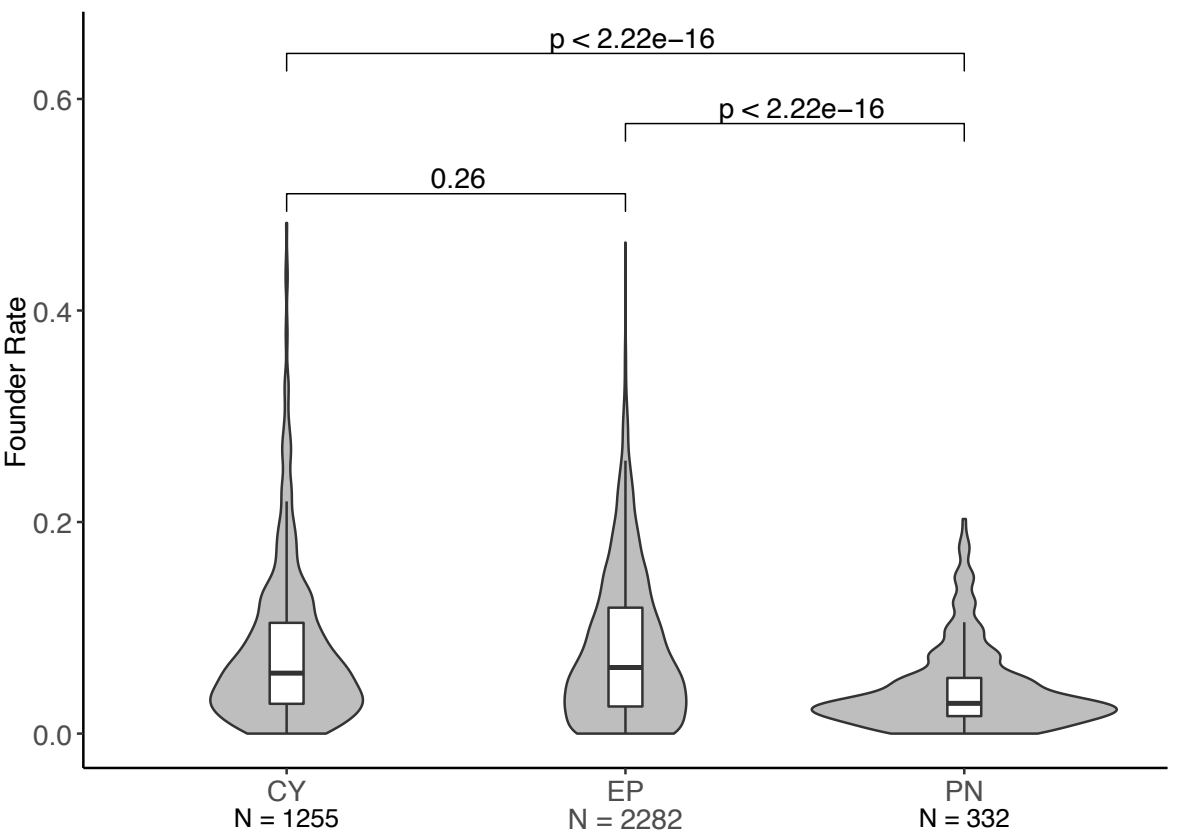

b

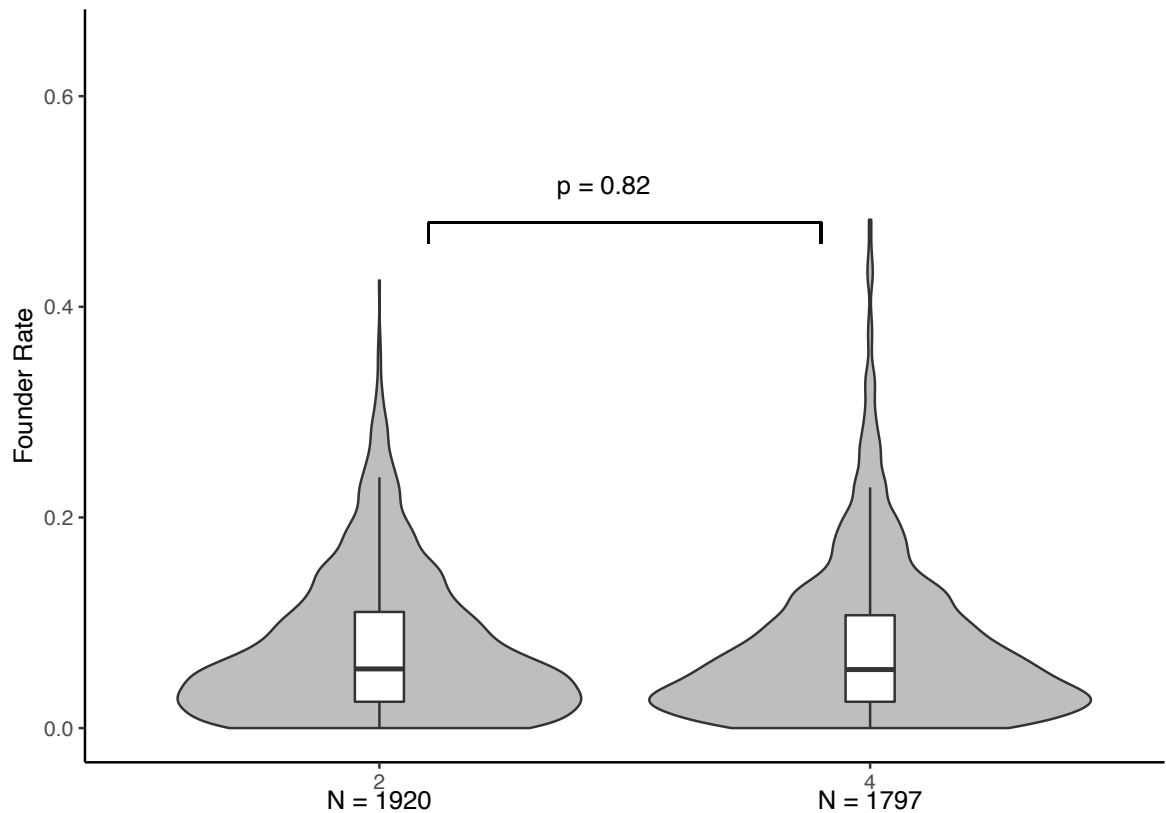




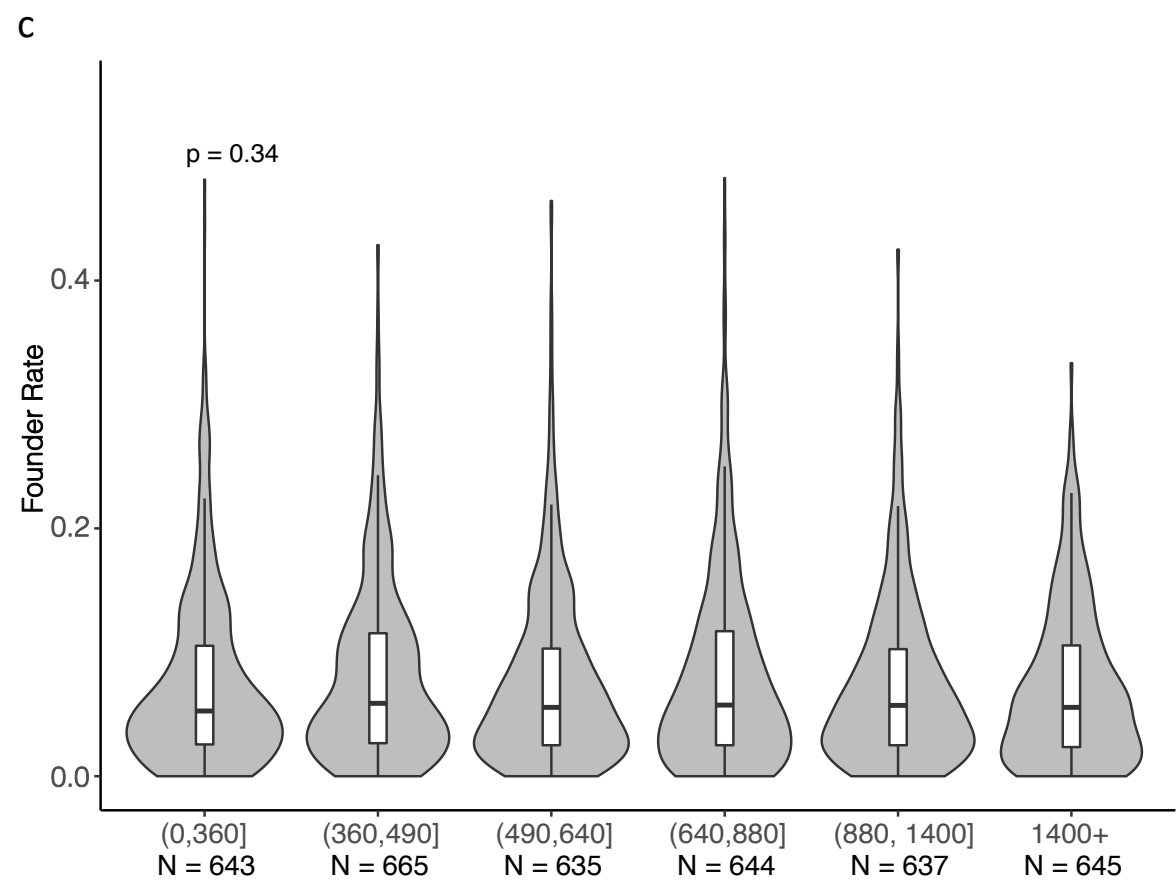

d

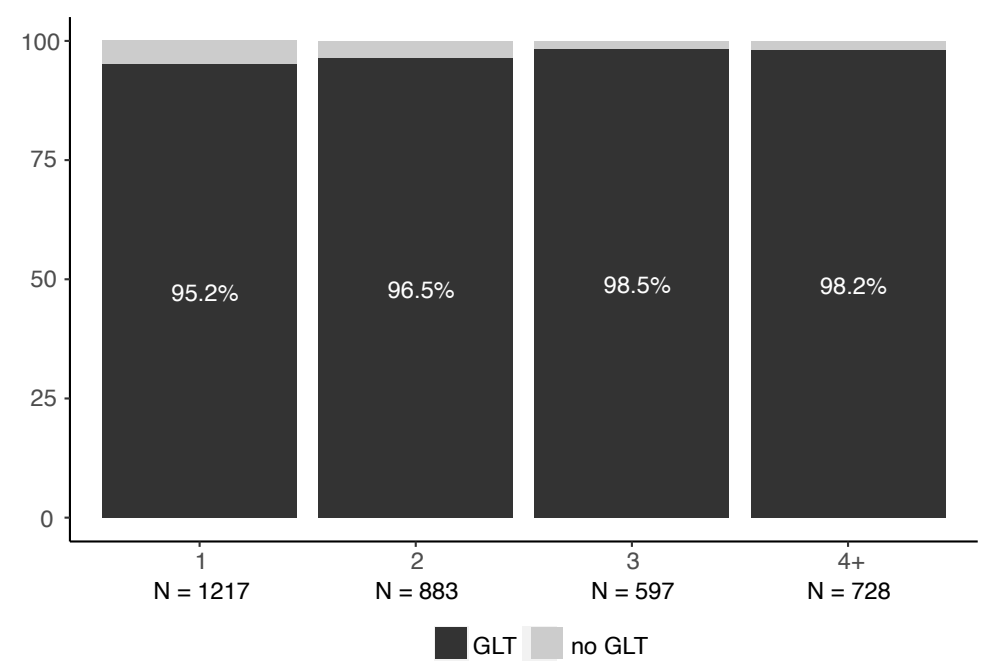

Figure 1. Experimental parameters affecting Cas9-mediated mutant mouse line production. a.

Founder rates from experiments with different methods of reagent delivery. $\mathrm{CY}$, cytoplasmic

injection; EP, electroporation; PN, pronuclear injection. b. Founder rates from experiments

using two (2) or four (4) guide RNAs designed to produce deletion alleles. c. Founder rates from experiments with Cas9 guide RNAs designed to delete different sizes of critical regions 
bioRxiv preprint doi: https://doi.org/10.1101/2021.10.06.463037; this version posted October 6, 2021. The copyright holder for this preprint

(which was not certified by peer review) is the author/funder, who has granted bioRxiv a license to display the preprint in perpetuity. It is made available under aCC-BY-NC 4.0 International license.

(genomic DNA). Each bin has 640 unique gene deletion attempts. d. Percentage of genes with GLT of the desired deletion allele after breeding one (1), two (2), three (3) or four or more (4+) founders. Pairwise comparison of GLT rates using the Holm method showed a significant difference only when breeding one founder was compared to breeding three or four founders ( $p=0.004$ for both comparisons). Unique gene attempts are the first attempt with GLT of the desired allele or the last of a set of unsuccessful attempts for each gene. See materials and methods for a complete description of data filtering. 
a

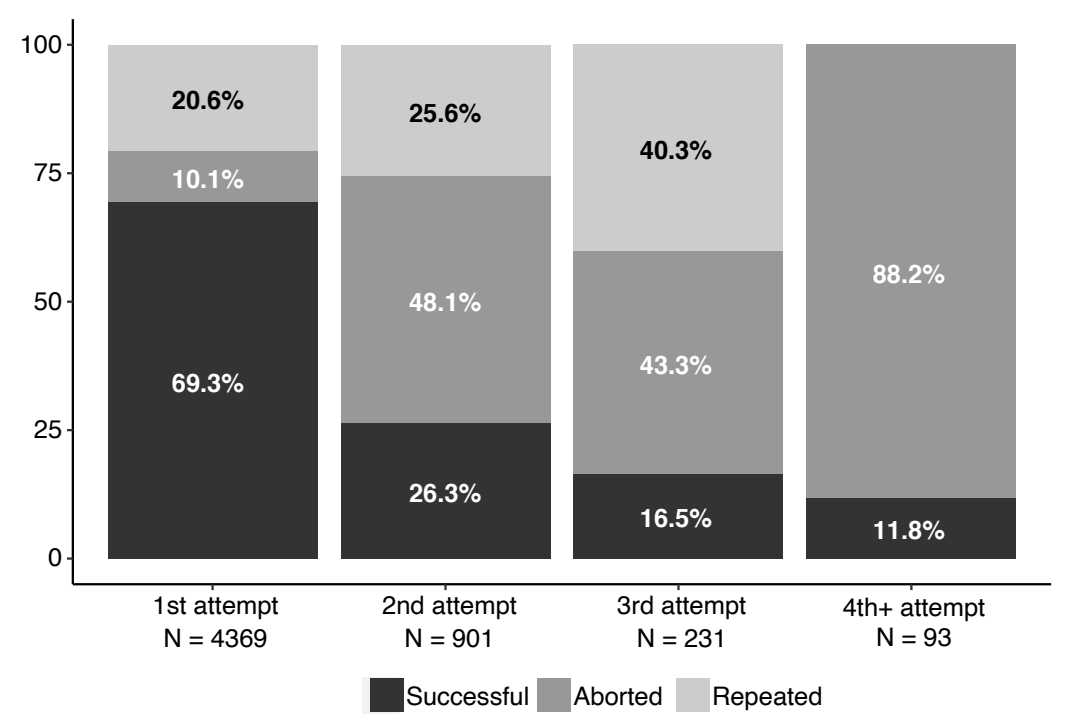

b
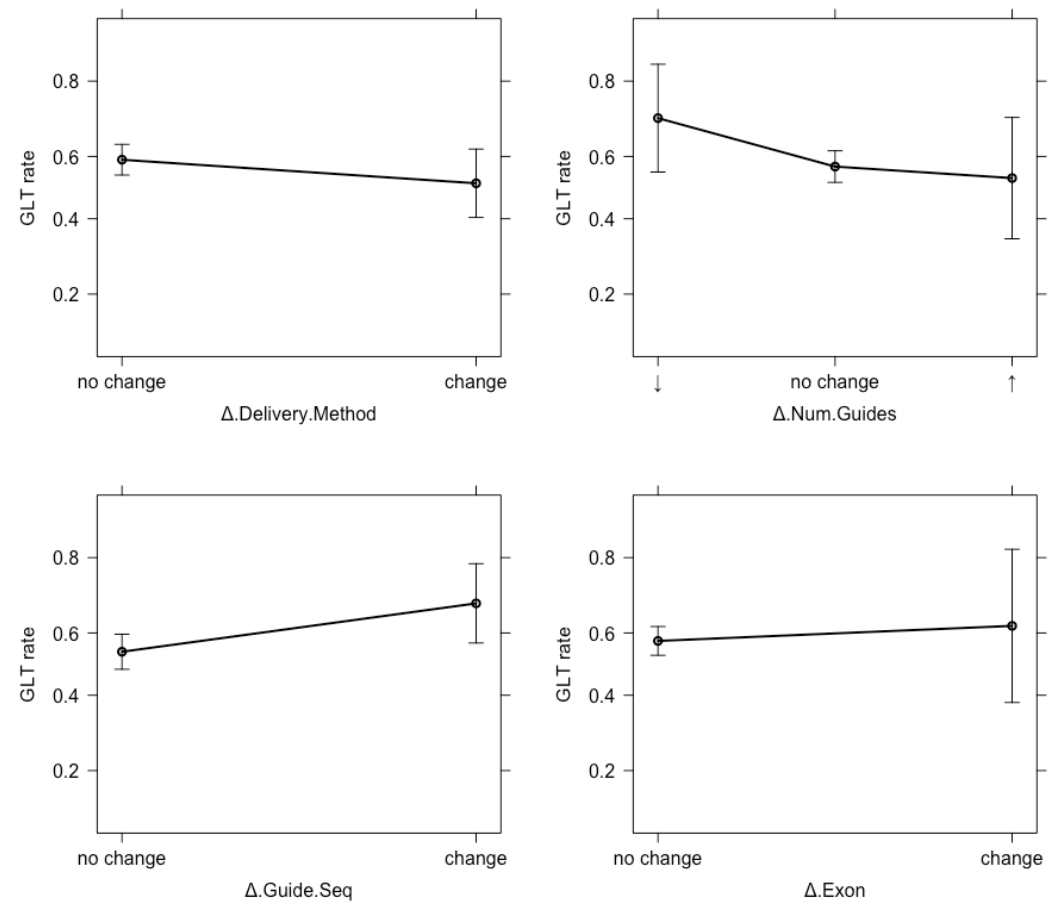

Figure 2. Percentage of genes with GLT of the desired allele. a. Percentage of genes with GLT of the desired deletion allele (successful), were abandoned with no additional attempts (aborted), or were repeated in subsequent experiments (repeated). b. Effect plots from the linear regression model. A negative slope indicates decreased GLT rates and a positive slope indicates 
bioRxiv preprint doi: https://doi.org/10.1101/2021.10.06.463037; this version posted October 6, 2021. The copyright holder for this preprint

(which was not certified by peer review) is the author/funder, who has granted bioRxiv a license to display the preprint in perpetuity. It is made available under aCC-BY-NC 4.0 International license.

increased GLT rates in subsequent attempts after the indicated parameter changed. See

materials and methods for a complete description of data filtering. 
bioRxiv preprint doi: https://doi.org/10.1101/2021.10.06.463037; this version posted October 6, 2021. The copyright holder for this preprint (which was not certified by peer review) is the author/funder, who has granted bioRxiv a license to display the preprint in perpetuity. It is made available under aCC-BY-NC 4.0 International license.

a

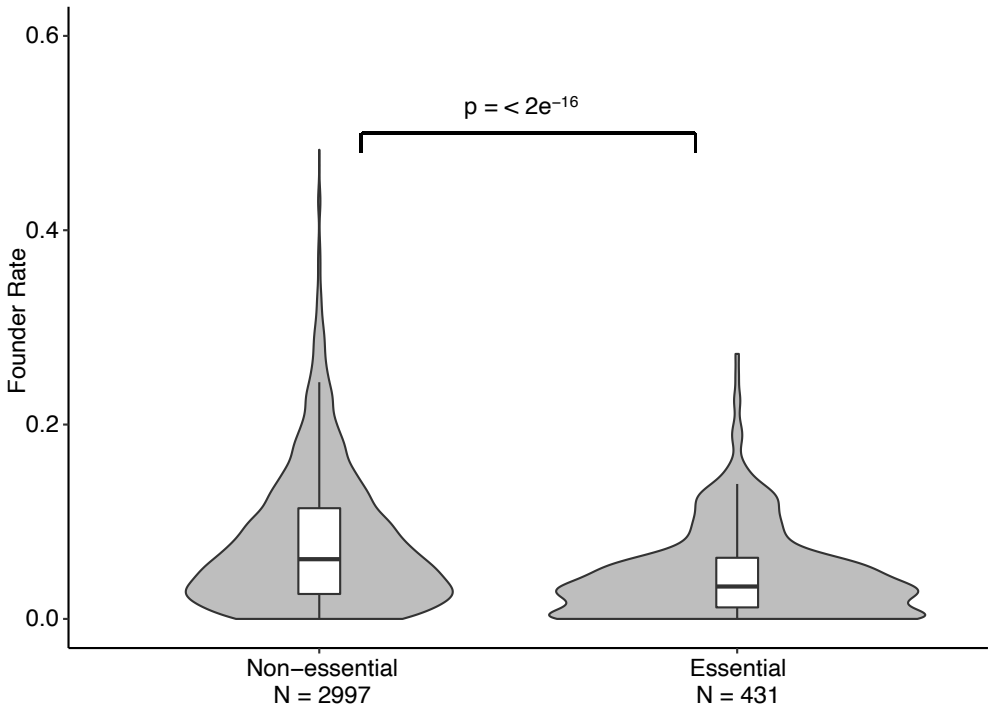

b

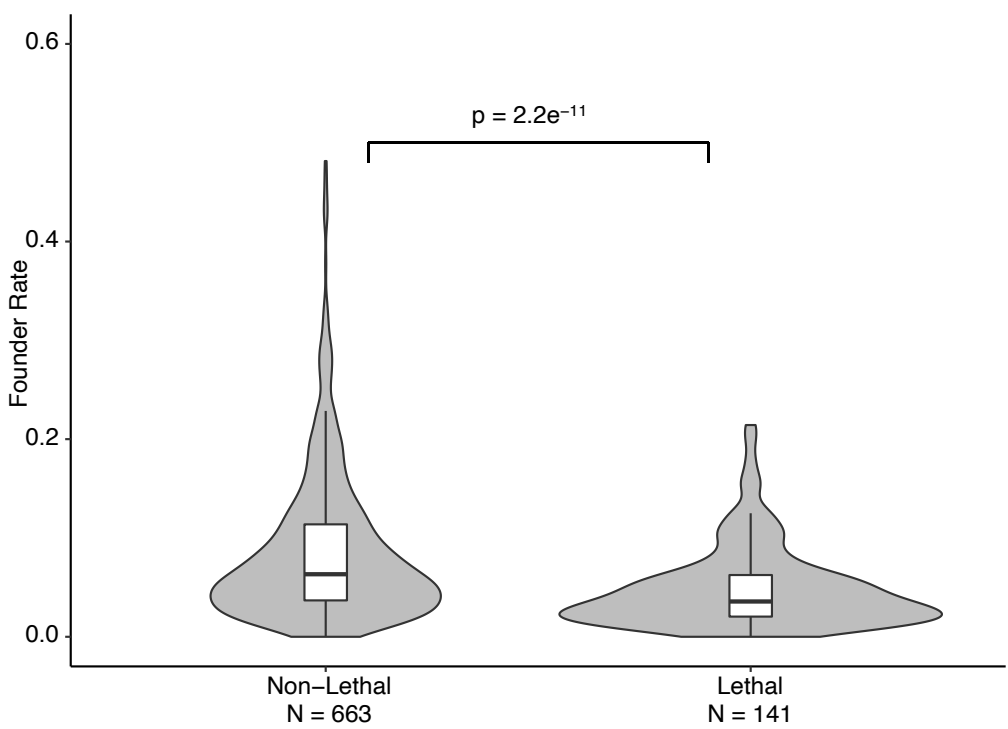


C

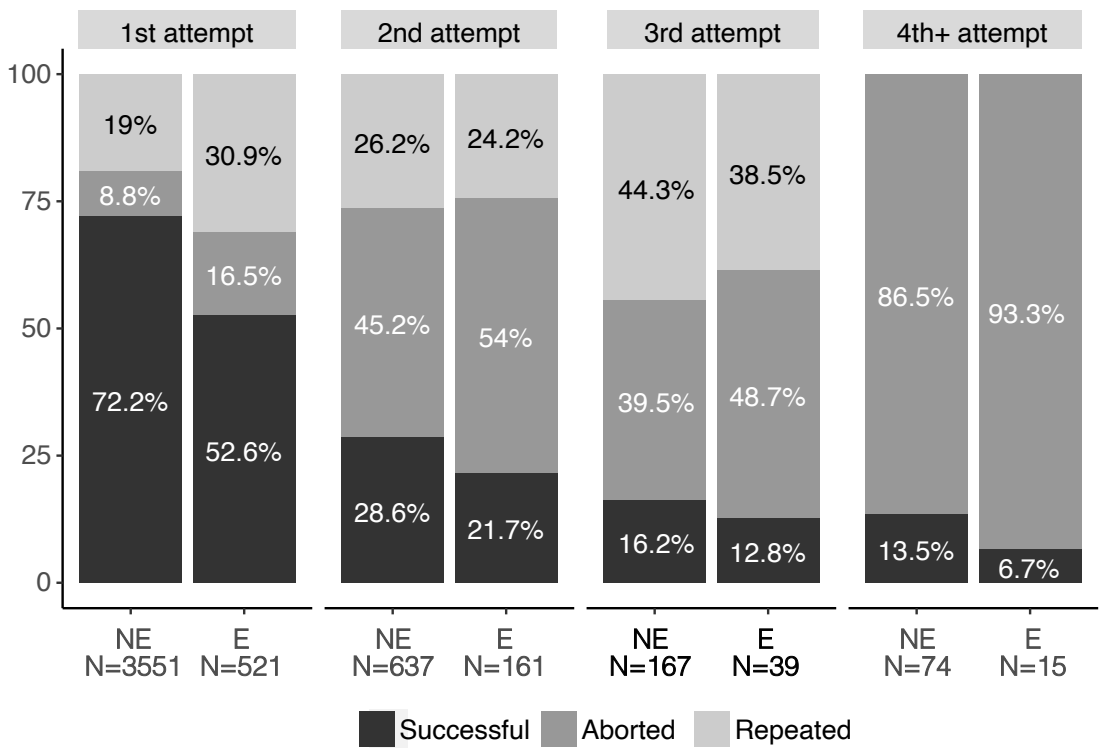

d

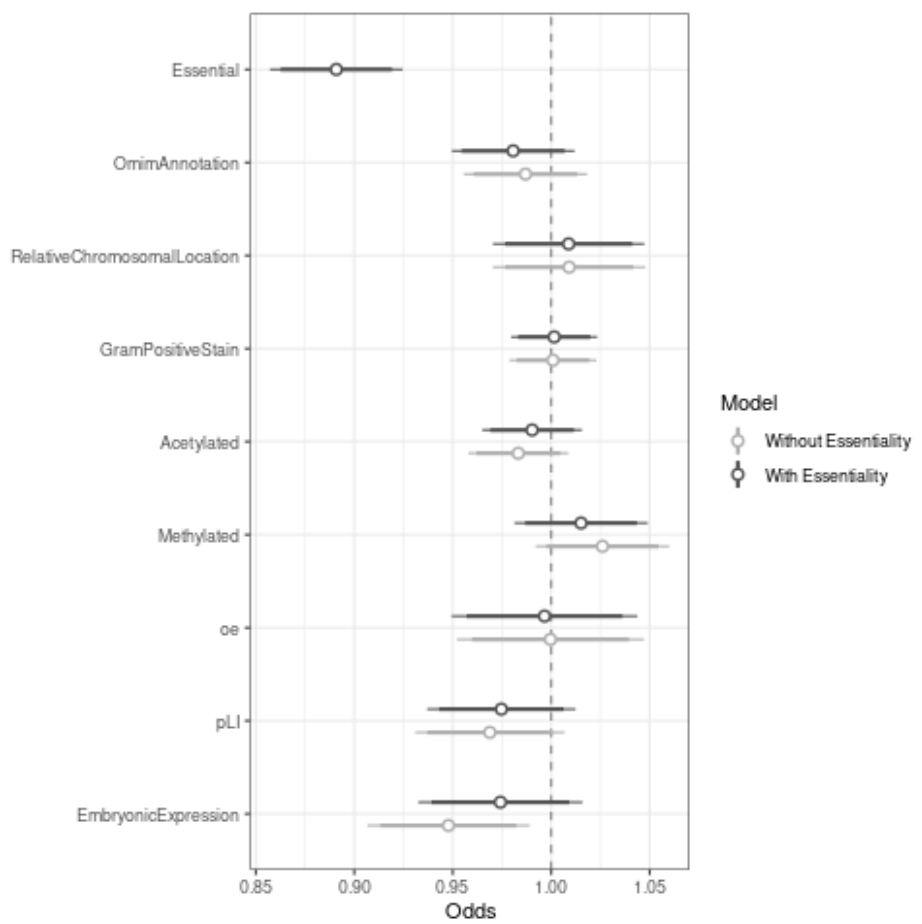

Figure 3. Effects of biological variables on founder and GLT rates for null allele production. a.

Founder rates of cellular non-essential and essential genes. b. Founder rates of homozygous

lethal and non-lethal genes. c. GLT of null alleles for essential (E) and non-essential (NE) genes

with multiple attempts to produce a null allele. $\mathbf{d}$. General linear model (GLM) showing the 
association of each variable with the success of the attempt to generate founders. An odds ratio below 1 is associated with a reduced probability of success, an odds ratio above 1 is associated with an improved probability of success, and an odds ratio of 1 is associated with no effect on success. Table 2 has the odds ratios and p-values for each variable, with and without essentiality in the model, that assess the significance of the difference of the estimate from zero. Supplemental Table 5 has the full model output. Each attempt represents a unique gene with the first attempt that successfully generated the desired allele or the last attempt of a set of unsuccessful attempts for each gene used for analysis. See materials and methods for a complete description of data filtering. 


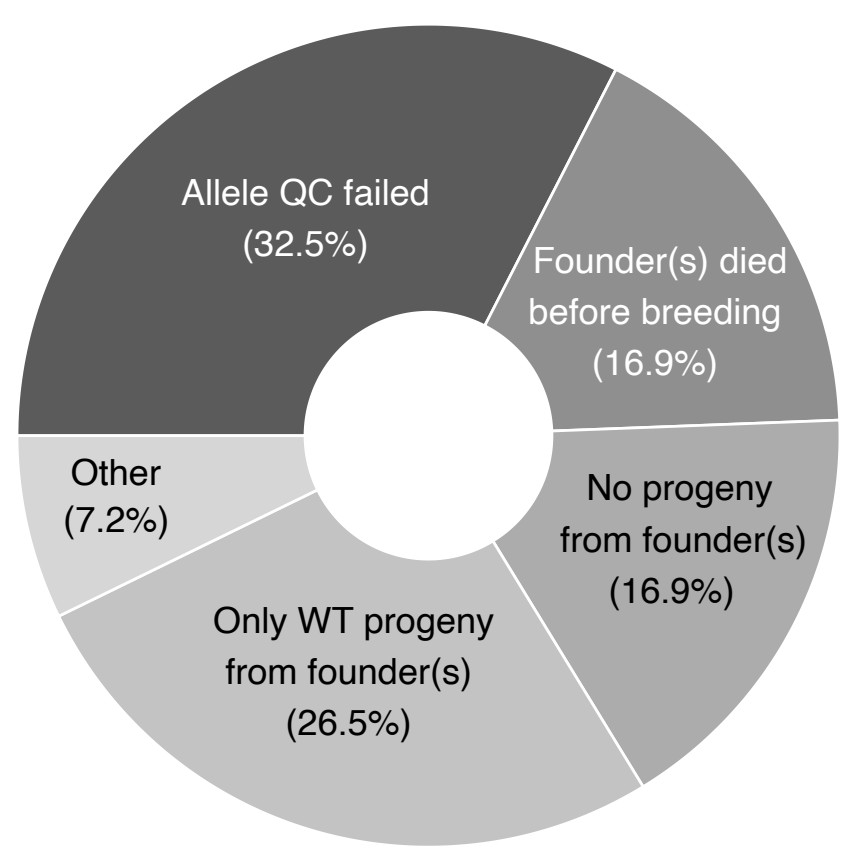

Figure 4. Summary of reasons for failure of founders to transmit a quality-controlled deletion allele to subsequent generations to establish a new knock-out mouse line. 
a

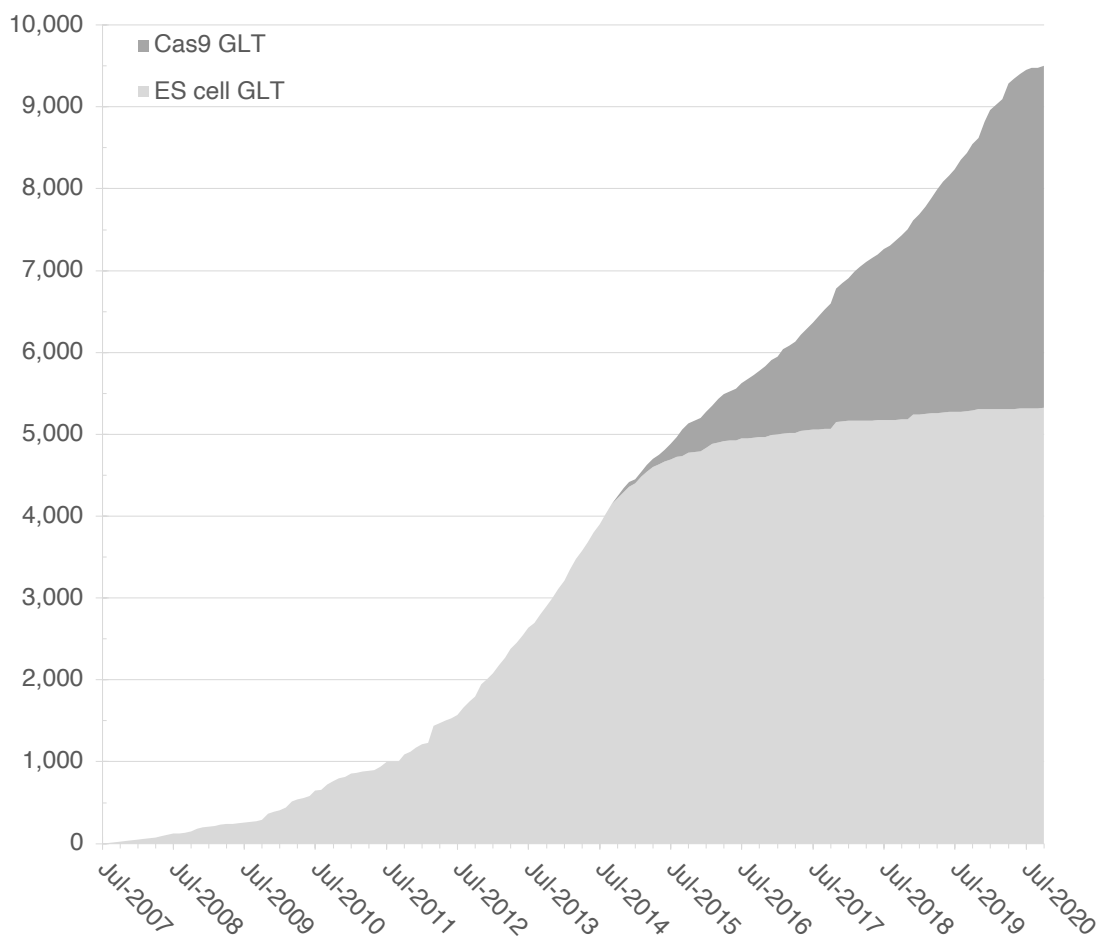

b

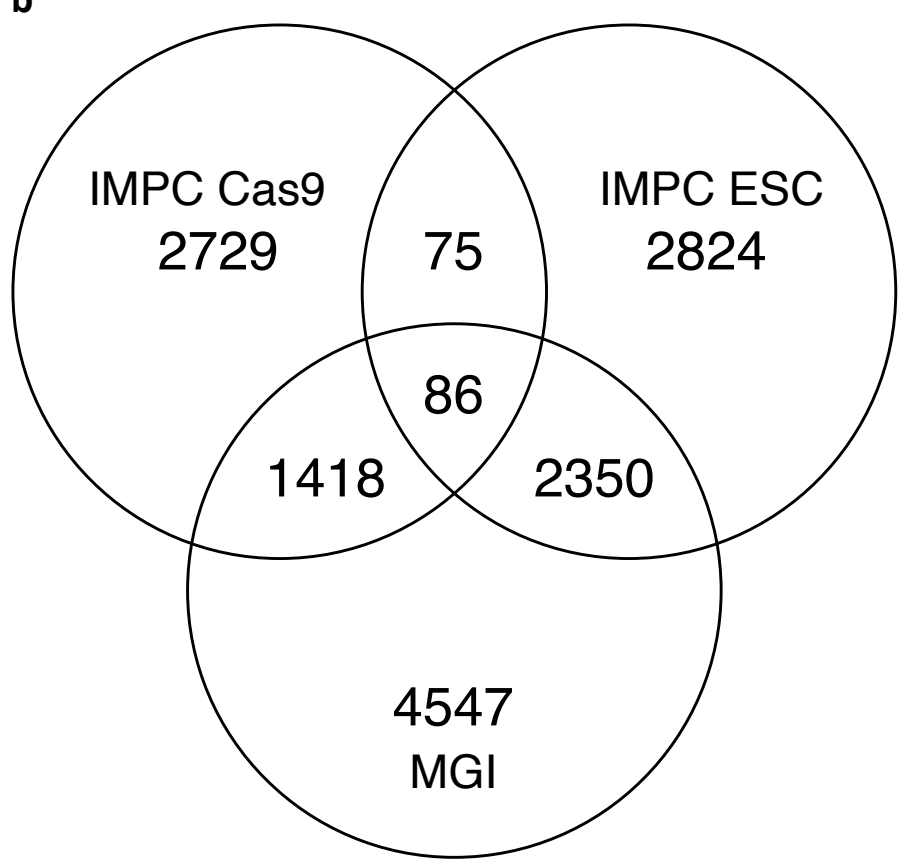

Figure 5. Production of a null mouse resource by the IMPC. a. Time course of progress to generate new unique knock-out lines (genes) by the IMPC and predecessor pilot projects. $\mathbf{b}$.

Venn diagram showing the overlap of protein-coding genes between IMPC Cas9- and embryonic 
bioRxiv preprint doi: https://doi.org/10.1101/2021.10.06.463037; this version posted October 6, 2021. The copyright holder for this preprint

(which was not certified by peer review) is the author/funder, who has granted bioRxiv a license to display the preprint in perpetuity. It is made available under aCC-BY-NC 4.0 International license.

stem cell (ESC)-derived knockout alleles and genes with knockout, conditional-ready or knock-

out reporter alleles registered in MGI not produced by the IMPC or using International

Knockout Mouse Consortium reagents (Supplemental Table 8). All IMPC lines are available

from their respective production centres or public repositories. 